\title{
Effects of high-diluted colloidal silica grouting on the behaviour of a liquefiable sand
}

\section{Giovanni Ciardi}

Department of Civil and Environmental Engineering, University of Florence, Florence, Italy (Orcid:0000-0003-3893-0548) (corresponding author: giovanni.ciardi@unifi.it)

\section{Roberto Bardotti}

Department of Civil and Environmental Engineering, University of Florence, Florence, Italy

\section{Giovanni Vannucchi}

Department of Civil and Environmental Engineering, University of Florence, Florence, Italy

Claudia Madiai

Department of Civil and Environmental Engineering, University of Florence, Florence, Italy

The effectiveness of colloidal silica (CS) treatment in increasing the liquefaction resistance of sandy soils is by now amply demonstrated. However, the best value of the CS content to achieve high performance, minimising economic cost and impact on buildings and the environment, has not yet been quantified. This paper presents the results of a laboratory study aimed to evaluate the influence of different CS contents on the behaviour of a liquefiable sand. The investigation included direct shear, cyclic triaxial, hydraulic conductivity and oedometer tests. CS contents 0,2 and $\mathbf{5 \%}$ (by weight) were used for all tests, except for direct shear tests (CS contents 0 and $2 \%$ ) and oedometer tests (CS contents $0,2,3,5,10$ and 13\%). The test results showed that $2 \%$ CS content was enough to increase the soil strength under cyclic and monotonic loading conditions. The hydraulic conductivity of treated soil decreased significantly as CS content increased. Oedometer tests pointed out that the main disadvantage of CS treatment is the soil compressibility increase. On the basis of the obtained results, $2 \%$ CS content seems to be recommended because it shows effectiveness and capability to improve the liquefaction resistance of sand while minimising the soil compressibility increase.

\section{Notation}

$a, b, c, d \quad$ best-fit parameters

B Skempton's coefficient

$C S_{\mathrm{W}} \quad$ colloidal silica content (percentage by weight of the grout)

$c^{\prime} \quad$ drained cohesion

$D_{50} \quad$ mean particle diameter

e void ratio

$e_{\mathrm{c}} \quad$ void ratio after consolidation

$e_{0} \quad$ initial void ratio

$e_{\max } \quad$ maximum void ratio

$e_{\min } \quad$ minimum void ratio

$G_{\mathrm{s}} \quad$ specific gravity

$I_{\mathrm{f}} \quad$ improvement factor

$k \quad$ hydraulic conductivity

$k_{10} \quad$ hydraulic conductivity at $10^{\circ} \mathrm{C}$

$N \quad$ number of loading cycles

$p^{\prime} \quad$ effective mean confining stress

$p_{\text {a }} \quad$ atmospheric pressure

$q \quad$ deviatoric stress

$R^{2} \quad$ coefficient of determination

$r_{\mathrm{u}} \quad$ pore water pressure ratio

$S_{\mathrm{h}} \quad$ horizontal displacement

$S_{\mathrm{v}} \quad$ vertical displacement

U uniformity coefficient

$\alpha \quad$ ratio of accelerant to the grout (by volume)

$\varepsilon_{\mathrm{a}} \quad$ axial strain

$\varepsilon_{\mathrm{DA}} \quad$ double amplitude axial strain

$\varepsilon_{\mathrm{q}} \quad$ deviatoric strain

$\varepsilon_{\mathrm{v}} \quad$ vertical strain

$\begin{array}{ll}\varepsilon_{\mathrm{vol}} & \text { volumetric strain } \\ \sigma_{\mathrm{c}}^{\prime} & \text { effective isotropic consolidation stress } \\ \sigma_{\mathrm{vc}}^{\prime} & \text { effective vertical consolidation stress } \\ \tau_{\mathrm{max}} & \text { maximum shear stress } \\ \phi^{\prime} & \text { peak angle of shearing resistance }\end{array}$

\section{Introduction}

In recent years, innovative remedial measures against liquefaction have been proposed and developed to improve the performance of liquefiable soils under cyclic loading conditions while minimising the economic cost and the impact on existing structures and infrastructures, as well as on the surrounding environment (Bao et al., 2019; Huang and Wen, 2015). These liquefaction countermeasures include techniques based on microbial processes, such as bio-cementation (DeJong et al., 2006; Montoya et al., 2013; Xiao et al., 2019) or bio-desaturation (He et al., 2013; Rebata-Landa and Santamarina, 2012); other techniques aiming to induce partial saturation, such as water electrolysis (Yegian et al., 2007), air injection (Okamura et al., 2011) or eco-friendly chemical treatment (Eseller-Bayat et al., 2012); and techniques based on the use of waste materials, like tyre chips (Mashiri et al., 2015; Zornberg et al., 2004), as well as of grouting materials, such as bentonite suspension or colloidal silica (CS) (El Mohtar et al., 2013; Gallagher and Mitchell, 2002; Gallagher et al., 2007a, 2007b).

To date, the in-field use of techniques based on microbial processes is limited because of difficulties in controlling biomediated processes, which can result in inhomogeneity of treatment and production of harmful by-products, such as ammonia (van Paassen et al., 2010a, 2010b). The main critical 
aspect of induced partial saturation treatments concerns the durability of gas/air bubbles in soils over time: if a full saturation condition is achieved again after a certain time, the treatment will not be effective any longer. Okamura et al. (2006) pointed out that a partial saturation condition lasted for more than 10 years in unsaturated soil under hydrostatic conditions. Tyre chips-sand mixtures show significantly higher compressibility than pure sand (Promputthangkoon and Hyde, 2007; Rao and Dutta, 2006), and it is questionable if their use is environmentally safe. Bentonite grouting suffers from the low mobility of the grout so that high injection pressures and/or chemical additives should be used to facilitate the grout permeation into the soil (Rugg et al., 2011; Yoon and El Mohtar, 2013).

CS grouting has some benefits in the above-mentioned aspects with respect to the other techniques. $\mathrm{CS}$ is a stable aqueous dispersion of silica $\left(\mathrm{SiO}_{2}\right)$ particles with size ranging from $2 \mathrm{~nm}$ up to $100 \mathrm{~nm}$. The CS dispersion can be destabilised (e.g. by the addition of an electrolyte solution) and the gelation process starts. During this process, particles settle, coalesce and develop siloxane (Si-O-Si) bonds (Iler, 1979). The formation of a silica-based gel is the consequence of bond development that results in a gradual increase in grout viscosity. The time to reach the gel state (known as 'gel time') can be adjusted by controlling ion concentration, the $\mathrm{pH}$, the size of silica particles, temperature and silica content (Agapoulaki and Papadimitriou, 2018; Gallagher and Lin, 2009; Gallagher and Mitchell, 2002; Persoff et al., 1999). Compared with the other innovative remedial measures against liquefaction, CS grouting has several attractive features because it combines the advantages of grouting (i.e. bonding of grains) with the benefits of easy injectability, environmental friendliness and durability.

Due to both small particle size and low initial viscosity, CS mixture can be delivered through the whole targeted volume of soil under low pressure (Bolisetti et al., 2009; Gallagher and Finsterle, 2004; Gallagher and Lin, 2009; Gallagher et al., 2007a; Hamderi and Gallagher, 2013, 2015). Thus, good uniformity of the treatment and a very limited disturbance to existing buildings/ infrastructures can be obtained (Gallagher et al., 2007a; Rasouli et al., 2016). The aqueous silica dispersion is nontoxic, chemically and biologically inert and does not cause pollution when injected in the soil (Huang and Wang, 2016). According to Whang (1995), the expected lifetime of CS is over 25 years.

Whereas the field performance of most innovative techniques for liquefaction mitigation still represents a challenge, CS grouting has been successfully used both for full-scale field tests and for the improvement of liquefiable areas at the Japanese airport of Fukuoka (Gallagher et al., 2007a; Rasouli et al., 2016).

For practical geotechnical applications, given a certain gel time, the CS dispersion is diluted to obtain the desired silica content; an appropriate choice of silica dilution is an essential requirement to maximise the ratio between effectiveness in soil improvement and cost. Gallagher and Mitchell (2002) performed cyclic triaxial tests on loose (relative density $22 \%$ ), uniform silica sand treated with CS (CS contents ranging from 5 to $20 \%$ by weight): by comparing the cyclic resistance of treated and untreated samples, they stated that $5 \%$ CS content represents a good compromise between the economic cost and the effectiveness of the treatment for liquefaction mitigation. The unconfined compressive strength resulting from tests performed on grouted sand was in the range $32-110 \mathrm{kPa}$ for CS contents in the range $5-15 \%$ by weight. Several other studies have been performed to investigate different aspects of the mechanical behaviour of liquefiable sands treated by CS grout at different silica concentrations, assuming 5\% CS content as a sort of lower limit for silica dilution (Díaz-Rodríguez et al., 2008; Gallagher et al., 2007a; Porcino et al., 2012; Rasouli et al., 2016; Spencer et al., 2007), whereas silica contents lower than $5 \%$ by weight have been used in a few studies. Towhata and Kabashima (2001) evaluated the cyclic performance of Toyoura sand treated with $4.5 \%$ silica grout; Kodaka et al. (2005) analysed the cyclic response of Toyoura sand treated with $4 \%$ silica grout; Conlee et al. (2012) evaluated the behaviour of untreated sands compared with that of sands treated with 4,5 and $9 \%$ silica grout by means of centrifuge tests. Hamderi and Gallagher (2015) analysed the grout delivery mechanism into a large-scale facility $(243 \times 366 \mathrm{~cm}$, $122 \mathrm{~cm}$ deep) filled with loose sand (relative density $22 \%$, hydraulic conductivity $1.8 \times 10^{-1} \mathrm{~cm} / \mathrm{s}$ ). They also measured the unconfined compressive strength and pocket penetrometer resistance of grouted sand and found that even $1 \%$ CS content was sufficient to bind the sand particles after a certain time (the unconfined compressive strength was measured in the range $10-120 \mathrm{kPa}$, which was considered enough to improve the liquefaction resistance of loose sand based on the findings of Gallagher and Mitchell (2002)). However, the main objective of the Hamderi and Gallagher (2015) study was to investigate the rate of grout delivery. Therefore, they have not analysed the effects of low CS concentrations on the soil response under cyclic conditions.

Lastly, none of the previous studies dealt with a comprehensive analysis of all the main effects of high-diluted $(<5 \%)$ CS treatment on the mechanical and physical properties of a given type of material (namely, stress-strain relationships and strength under cyclic dynamic and static monotonic loading conditions, dilatancy, soil compressibility and hydraulic conductivity). Each study analysed only a few aspects of the behaviour of the tested soil, often focusing only on the effectiveness of the treatment to improve the soil behaviour in cyclic conditions. However, in view of possible on-site applications, it is necessary to consider not only the effects of the treatment on the soil response under cyclic or monotonic loading conditions but also the changes in soil compressibility and hydraulic conductivity after grouting. The variation in hydraulic conductivity shall be assessed to determine the impact of the grouting on the hydraulic conditions and aquifer flow. Moreover, the effects of the CS treatment on both the strength parameters under static conditions and the compressibility parameters must be evaluated to verify the stability conditions of the structures that interact with the treated subsoil volume. 
In most previous research (Dìaz-Rodrìguez et al., 2008; Gallagher and Lin 2009; Gallagher and Mitchell 2002; Gallagher et al., 2007a; Georgiannou et al., 2017; Persoff et al., 1999; Rasouli et al., 2016, among others), CS contents were chosen in the range $5-30 \%$ by weight of the grout. In contrast, the primary objective of this study is to analyse the effects of treatment with low CS concentrations (down to $2 \%$ by weight) on a given soil, which is susceptible to seismic liquefaction based on its grain size distribution, because reducing CS contents means a reduction of the grout cost. The study is comprehensive of laboratory investigations on soil response under cyclic and static monotonic loading conditions, hydraulic conductivity and soil compressibility. The CS contents adopted in this research are in the range $2-5 \%$ for most laboratory tests, as discussed in the following sections, except for compressibility tests, where $2-13 \%$ silica contents were used. Although it is generally accepted that CS grouting modifies the soil response, its effects on a clean sand have not been extensively quantified for CS contents down to $2 \%$ by weight. Therefore, in this study, the effectiveness of treatment with high-diluted CS solution on the soil liquefaction resistance was first proven by cyclic triaxial tests. Then, the effects on the strength parameters and on dilatancy under static loading conditions were evaluated by means of direct shear tests. These tests aim to verify if the wellknown benefits of CS grouting in terms of increased liquefaction resistance and improved static shear strength are maintained even if a very low CS content solution is used. Permeability tests allowed quantifying the variation in hydraulic conductivity. For practical application, this information is useful to know how the CS treatment modifies the groundwater flow and to assess the possible impact on surrounding built-up areas. Finally, oedometric tests were performed to analyse the effects of CS grouting on soil compressibility. This aspect has been almost completely neglected in previously published works. Furthermore, the results of oedometric tests on CS grouted sand previously reported in the literature (Georgiannou et al., 2017; Wong et al., 2018) are not directly comparable because of the differences in the specimens' formation method, in CS contents and in the kind of materials tested. On the other hand, the compressibility of CS gel, and consequently of the treated soil, represents a critical issue for engineering practice because a significant induced ground settlement could result in damage to structures and constructed facilities laying on CS grouted soil deposits. Therefore, in order to better investigate the effect of CS treatment on soil compressibility, a wider range of silica contents $(2-13 \%)$ was adopted in performing the oedometer tests.

After the description of all the experimental procedures used in this study, the results of the tests carried out both on untreated material and treated samples are discussed and compared with those obtained from other authors on different or similar sands and testing conditions.

\section{Experimental programme and materials}

An experimental laboratory study was performed to clarify some fundamental aspects of the possible use of high-diluted CS grouting for practical applications. Treated and untreated sand samples were tested to evaluate the effects induced by the CS treatment on the main mechanical and hydraulic soil properties. Analysing the behaviour of sands treated by solutions with silica content in the range $5-30 \%$ by weight, previous studies have clearly shown that, as the silica content increases, the static and cyclic soil strength increases, whereas the hydraulic conductivity significantly decreases (Díaz-Rodríguez et al., 2008; Gallagher and Mitchell, 2002; Georgiannou et al., 2017; Nouri Delavar and Noorzad, 2020; Persoff et al., 1999; Porcino et al., 2012; Vranna and Tika, 2015). On the other hand, the effect induced by the CS treatment on the soil compressibility has not yet been clarified. For a given CS content, it is not clear whether the CS treatment causes an increase or a decrease in the compressibility of the treated soil (Ciardi et al., 2019; Georgiannou et al., 2017; Wong et al., 2018).

The laboratory tests performed in this study included undrained cyclic triaxial tests, direct shear tests, hydraulic conductivity measurements and one-dimensional (1D)-confined compression tests (oedometer tests). First, 0, 2 and 5\% silica contents were adopted for cyclic triaxial tests, and it was found that $2 \% \mathrm{CS}$ provides a significant increase in liquefaction resistance. Therefore, only 0 and 2\% silica concentrations were used in direct shear tests, whereas the hydraulic conductivity was measured for sand treated with 0,2 and $5 \% \mathrm{CS}$ because of its great variability. A wider range of silica contents $(0,2,3,5,10$ and 13\%) was finally used in performing oedometer tests to better investigate the effects of the treatment on the soil compressibility, which was considered an important aspect still little explored.

A clean, uniform, mainly siliceous sand, named S3 sand, was used for all tests. It is a subrounded, low-sphericity grain sand; its grain distribution is shown in Figure 1 and compared with the grain distribution curves of other literature sands. S3 sand is classified as SP material (Unified Soil Classification System) and it is characterised by specific density $G_{\mathrm{s}}=2.65$, uniformity coefficient $U=1.6$, mean particle diameter $D_{50}=0.30 \mathrm{~mm}$,

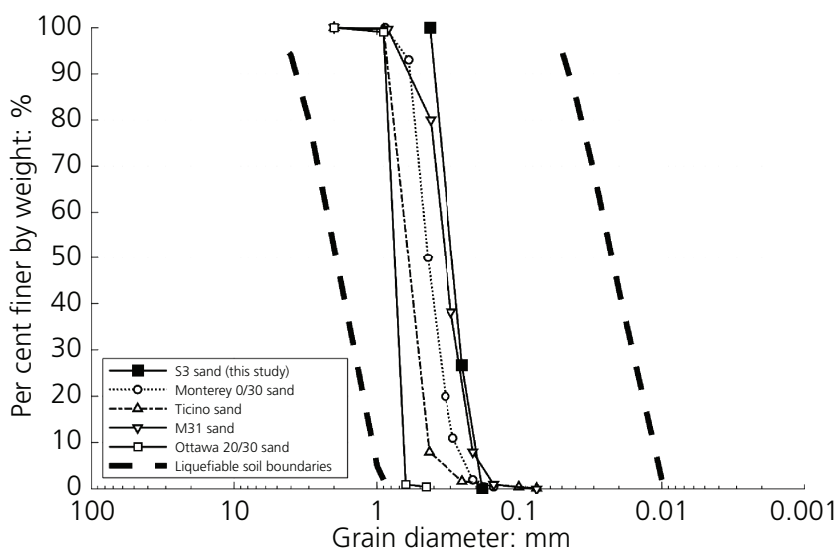

Figure 1. Grain size distribution of S3 sand compared with sands from other studies 
maximum and minimum void ratio $e_{\max }=0.839$ and $e_{\min }=0.559$ (measured according to DIN 18126 (DIN, 1996)), respectively.

MasterRoc ${ }^{\circledR}$ MP 325 (BASF SE) was selected as the CS product: it is supplied as a clear solution with $15 \pm 1 \%$ (by weight) silica content, a viscosity of $\approx 10 \mathrm{mPa} \cdot \mathrm{s}\left(20^{\circ} \mathrm{C}\right)$, a density of $\approx 1.1 \mathrm{~kg} / 1$ $\left(20^{\circ} \mathrm{C}\right)$ and $\mathrm{pH}$ of $10 \pm 1\left(20^{\circ} \mathrm{C}\right)$. To catalyse the gelation reaction, a sodium chloride $(\mathrm{NaCl})$ solution (referred to as the accelerant in this paper) was prepared by mixing demineralised water and sodium chloride with a ratio of 10:1 (by weight); the grout used for treatments was finally made of distilled water, accelerant, and MasterRoc ${ }^{\circledR}$ MP 325 mixed at various ratios, depending on the desired initial silica content, which is intended as the percentage (by weight) of silica particles in the grout and indicated as $C S_{\mathrm{W}}$ thereafter. All experiments were carried out at room temperature $\left(20 \pm 1^{\circ} \mathrm{C}\right)$; no adjustment to the $\mathrm{pH}$ of the grout was made. All tests were performed assuming a gel time of approximately $120 \mathrm{~min}$ and curing time (the time interval between the end of gelation and the beginning of each test) of 5 days. The gel time was adjusted by varying parameter $\alpha$, defined as the ratio between the volume of the accelerant and the total volume of the grout. The minimum $C S_{\mathrm{W}}$ adopted in this study is $C S_{\mathrm{W}}=2 \%$ because there was no gel formation for lower CS content grouts (i.e. the mixture remained in liquid state).

\section{Cyclic triaxial tests}

To investigate the effectiveness of CS grouting in improving the cyclic liquefaction resistance, undrained stress-controlled cyclic triaxial tests were performed on treated $\left(C S_{\mathrm{W}}=2 \%, 5 \%\right)$ and untreated $\left(C S_{\mathrm{W}}=0 \%\right)$ cylindrical specimens $(50 \mathrm{~mm}$ diameter, $100 \mathrm{~mm}$ height).

Two different reconstitution methods were used to obtain dense or loose sand specimens. Dense untreated sand specimens were formed by tamping dry sand into a split mould to achieve the desired initial void ratio. Because dense sand specimens generally show a dilative behaviour at relatively low confining pressures, such as those investigated in this study, dense treated sand specimens were not tested. Loose untreated sand specimens were prepared by pluviating dry sand into a split mould partly filled with distilled and deaired water so that sand grains were kept under the liquid level during the whole formation process. In the same way, loose treated sand samples were prepared by pluviating dry sand into a split mould filled with CS grout in liquid state, always maintaining the sand grains below the grout level. This gel sedimentation technique has been previously used by several researchers; it allows uniformity grout distribution and ensures full gel-saturation (Díaz-Rodríguez et al., 2008; Gallagher and Mitchell, 2002; Georgiannou et al., 2017). After preparation, samples were sealed and were left to cure at room temperature and humidity before testing. Once placed into the triaxial cell, untreated sand specimens were saturated with deaired water by applying a back pressure (Skempton's coefficient $B \geq 0.95$ ); treated specimens, on the contrary, were not water-saturated before being sheared ( $B$-value was not measured for gel-saturated material), to avoid back pressure breaking the weak gel bonds and producing disturbance to the soil-gel structure.

Avoiding the back-pressurisation procedure is considered the safer way to eliminate any specimen disturbance, as discussed by some authors (Gallagher and Mitchell, 2002; Mollamahmutoglu and Yilmaz, 2010; Vranna and Tika, 2015). A sinusoidal symmetrical vertical load of a given amplitude was applied at a frequency of $0.1 \mathrm{~Hz}$ to each specimen isotropically consolidated at $\sigma_{\mathrm{c}}{ }^{\prime}=$ $100 \mathrm{kPa}$. The ratio between half of the maximum deviatoric stress $(q)$ and the initial effective confining pressure is defined as the cyclic stress ratio (CSR). For each treated specimen, the void ratio after consolidation $\left(e_{\mathrm{c}}\right)$ in the triaxial cell was estimated using the bulk modulus calculated from a confined compression test on a specimen with initial void ratio $\left(e_{0}\right)$ and $C S_{\mathrm{W}}$ equal to that of the specimen tested in the triaxial apparatus, assuming the soil as linear elastic, homogeneous and isotropic. These assumptions are justified by the low applied confining pressure, the sand characteristics and the technique of specimen formation.

According to widely used conventional criteria (Ishihara, 1993), liquefaction (or failure) of untreated sand was assumed to occur for a number of loading cycles $N$, when the ratio of the excess pore water pressure over the initial consolidation effective stress $\left(r_{\mathrm{u}}\right)$ was equal to 1.0 (stress criterion) or, alternatively, when the double amplitude axial strain $\left(\varepsilon_{\mathrm{DA}}\right)$ reached $5 \%$ (strain criterion). For untreated material, it is worth saying that a sudden increase of $\varepsilon_{\mathrm{DA}}$ was recorded if $r_{\mathrm{u}}=1.0$, during tests CTT-3-CTT-11 (Table 1) whereas complete loss of strength did not take place in tests CTT-1 and CTT-2 (Table 1) for which the strain criterion was used to define the state of cyclic instability. The pore pressure was not measured for treated sand samples because they were not water-saturated by back-pressurisation after gel-saturation during the formation process. Furthermore, because silica gel is more compressible than water (' $1 \mathrm{D}$-confined compression tests' section), the $r_{\mathrm{u}}$ measurement cannot have the same meaning as for untreated sand. As stated by Conlee et al. (2012: p. 1339), 'although liquefaction is conventionally defined as the time when $r_{\mathrm{u}}=$ 1.0 , the significance of $r_{\mathrm{u}}$ for CS sand does not represent the same physical meaning'. Thus, the occurrence of 5\% DA axial strain was used as a criterion to define coherently the state of failure condition for treated sand. No failure was assumed when $N$ exceeded 100, both for treated and untreated sands. Test details are reported in Table 1.

\section{Direct shear tests}

Direct shear tests were performed on treated $\left(C S_{\mathrm{W}}=2 \%\right)$ and untreated $\left(C S_{\mathrm{W}}=0 \%\right)$ material to investigate the effects of $2 \% \mathrm{CS}$ grouting on the soil strength parameters. Untreated loose sand specimens were prepared by pouring dry sand into the (square) steel mould inside the shear box, whereas treated sand samples were prepared on a plexiglass plate outside the shear box by pluviating dry sand into a steel mould containing the CS liquid mixture, keeping the sand particles below its level. The amount of grout was equal to the calculated volume of voids; silicon grease was put at the bottom of the mould to avoid seepage. After gelation, the samples were extruded with a tamper and put in the 
Table 1. Cyclic triaxial and direct shear test details

\begin{tabular}{|c|c|c|c|c|c|c|c|c|c|}
\hline \multicolumn{6}{|c|}{ Cyclic triaxial tests } & \multicolumn{4}{|c|}{ Direct shear tests } \\
\hline ID & $C S_{W}: \%$ & $e_{c}$ & CSR & $N\left(r_{\mathrm{u}}=1\right)$ & $N\left(\varepsilon_{\mathrm{a}}=5 \%\right)$ & ID & $C S_{W}: \%$ & $\sigma_{\mathrm{vc}}^{\prime}: \mathrm{kPa}$ & $e_{c}$ \\
\hline CTT-1 & 0 & 0.657 & 0.20 & No & 37.5 & DST-1 & 0 & 98 & 0.778 \\
\hline CTT-2 & 0 & 0.673 & 0.20 & No & 55.5 & DST-2 & 0 & 196 & 0.778 \\
\hline CTT-3 & 0 & 0.670 & 0.27 & 6 & - & DST-3 & 0 & 294 & 0.770 \\
\hline CTT-4 & 0 & 0.667 & 0.27 & 8 & - & DST-4 & 2 & 98 & 0.778 \\
\hline CTT-5 & 0 & 0.668 & 0.32 & 3.5 & - & DST-5 & 2 & 196 & 0.775 \\
\hline СТT-6 & 0 & 0.654 & 0.26 & 10 & - & DST-6 & 2 & 294 & 0.744 \\
\hline CTT-7 & 0 & 0.745 & 0.16 & 6 & - & DST-7 & 0 & 48 & 0.778 \\
\hline CTT-8 & 0 & 0.765 & 0.11 & No failure & No failure & DST-8 & 2 & 49 & 0.776 \\
\hline CTT-9 & 0 & 0.776 & 0.13 & 77 & - & DST-9 & 2 & 147 & 0.774 \\
\hline CTT-10 & 0 & 0.772 & 0.15 & 22 & - & - & - & - & - \\
\hline СТT-11 & 0 & 0.721 & 0.18 & 5 & - & - & - & - & - \\
\hline СТT-12 & 5 & 0.779 & 0.26 & n.m. & 1.5 & - & - & - & - \\
\hline СТT-13 & 5 & 0.779 & 0.20 & n.m. & No failure & - & - & - & - \\
\hline СТT-14 & 5 & 0.763 & 0.29 & n.m. & 3.5 & - & - & - & - \\
\hline СТT-15 & 5 & 0.760 & 0.38 & n.m. & 0.7 & - & - & - & - \\
\hline СТT-16 & 5 & 0.760 & 0.28 & n.m. & 6.5 & - & - & - & - \\
\hline CTT-17 & 5 & 0.787 & 0.37 & n.m. & 0.7 & - & - & - & - \\
\hline СТT-18 & 2 & 0.783 & 0.17 & n.m. & No failure & - & - & - & - \\
\hline СТT-19 & 2 & 0.754 & 0.28 & n.m. & 1.7 & - & - & - & - \\
\hline СТT-20 & 2 & 0.782 & 0.26 & n.m. & 3.5 & - & - & - & - \\
\hline СТT-21 & 2 & 0.755 & 0.23 & n.m. & 6.5 & - & - & - & - \\
\hline СTT-22 & 2 & 0.788 & 0.22 & n.m. & 4.5 & - & - & - & - \\
\hline СТT-23 & 2 & 0.776 & 0.27 & n.m. & 1.7 & - & - & - & - \\
\hline
\end{tabular}

CSR, cyclic stress ratio; $C S_{W}$, colloidal silica content; $e_{c}$, void ratio after consolidation; ID, identification code; $N$, number of loading cycles at failure; n.m., not measured; $\sigma_{\mathrm{vc}}^{\prime}$, vertical effective consolidation pressure

shear box; then, the shear chamber was filled with water. Treated samples were kept underwater during curing time, whereas untreated samples were kept underwater for one night. All specimens (squared, $20 \mathrm{~mm}$ height, $60 \times 60 \mathrm{~mm}^{2}$ area) were consolidated by applying different effective vertical consolidation pressures, $\sigma_{\mathrm{vc}}^{\prime}$, for $24 \mathrm{~h}$ before shearing. A slow displacement rate $(0.03$ and $0.0015 \mathrm{~mm} / \mathrm{min}$ for untreated and treated sands, respectively) was used during the shearing phase to avoid the generation of pore pressure. The failure condition was assumed at the maximum shear stress, $\tau_{\max }$, recorded during the shearing phase. Test details are listed in Table 1 .

\section{Hydraulic conductivity tests}

In view of its possible use for practical applications, an important impact of CS treatment involves the decrease in the subsoil permeability. The hydraulic conductivity $(k)$ of grouted specimens was therefore evaluated to investigate the effects of low-content CS grout on water flow. In this study, a dedicated triaxial cell was used to measure the hydraulic conductivity of untreated $\left(C S_{\mathrm{W}}=\right.$ $0 \%)$ and treated sand $\left(C S_{\mathrm{W}}=2 \%, 5 \%\right)$. Cylindrical specimens $(50$ $\times 100 \mathrm{~mm}$ ) were prepared inside a latex membrane by pouring and tamping dry sand into a split mould; once the triaxial cell was assembled, a small confining pressure $(20 \mathrm{kPa})$ was applied to sustain the samples. They were then flushed with carbon dioxide for about half an hour to facilitate air removal and finally saturated with distilled and deaired water. After saturation, the hydraulic conductivity of untreated sand was measured in falling head mode and recorded; temperature correction, with reference to a value of $10^{\circ} \mathrm{C}$, was made according to the standard EN ISO 17892-11:2019 (ISO, 2019). Specimens were not consolidated. Solutions of $500 \mathrm{ml}$ of grout were prepared and used to permeate the water-saturated samples from the bottom end to the top end in falling head mode under low hydraulic gradients (defined as the ratio between the head difference at the ends of the specimen and the specimen's height), ranging from 1.5 to approximately 0.5 . Because the gradual increase of grout viscosity reduced its mobility (Bolisetti et al., 2009; Gallagher and Lin, 2009), parameter $\alpha$ was experimentally calibrated to ensure that a significant volume of grout passed throughout the samples before initial gelation: at least three pore volumes of grout were expected to pass through the specimens to ensure grout saturation. $\alpha=0.40$ and $\alpha=0.25$, for 2 and $5 \% C S_{\mathrm{W}}$, respectively, allowed the delivery of almost three pore volumes of grout; decreasing the amount of accelerant and using $\alpha=0.30$ for $C S_{\mathrm{W}}=2 \%$ and $\alpha=$ 0.15 for $C S_{\mathrm{W}}=5 \%$, approximately $480 \mathrm{ml}$ (more than five times the pore volume of the specimen) passed through the specimen without interruption. After grouting, the specimens were left to gel for 1 day before undertaking hydraulic conductivity measurements (approximately 1-day curing time). For realistic measurements, the triaxial drainage lines were previously cleaned from the gelled fluid. Test details are summarised in Table 2.

\section{D-confined compression tests}

Silica gel is expected to be more compressible than water. Towhata (2008) reported that the Poisson's ratio of a $6.5 \%$ pure CS sample measured in unconfined compression strength tests 
Table 2. Hydraulic conductivity and oedometer test details

\begin{tabular}{|c|c|c|c|c|c|c|c|c|c|}
\hline \multicolumn{6}{|c|}{ Hydraulic conductivity tests } & \multicolumn{4}{|c|}{ Oedometer tests } \\
\hline ID & $C S_{W}: \%$ & $e_{0}$ & $\alpha$ & $k_{10}: \mathrm{m} / \mathrm{s}$ & $k_{10} * \mathrm{~m} / \mathrm{s}$ & ID & $C S_{W}: \%$ & Method & $e_{0}$ \\
\hline HCT-1 & 2 & 0.680 & 0.40 & $3.29 \times 10^{-4}$ & $3.45 \times 10^{-8}$ & OED-1 & 0 & - & 0.777 \\
\hline HCT-2 & 2 & 0.695 & 0.30 & $1.68 \times 10^{-4}$ & $5.75 \times 10^{-8}$ & OED-2 & 5 & 1 & 0.795 \\
\hline HCT-3 & 2 & 0.680 & 0.30 & $2.48 \times 10^{-4}$ & $2.19 \times 10^{-8}$ & OED-3 & 2 & 1 & 0.789 \\
\hline HCT-4 & 5 & 0.659 & 0.25 & $2.41 \times 10^{-4}$ & $3.82 \times 10^{-9}$ & OED-4 & 2 & 1 & 0.800 \\
\hline HCT-5 & 5 & 0.666 & 0.15 & $2.55 \times 10^{-4}$ & $1.50 \times 10^{-9}$ & OED-5 & 5 & 1 & 0.805 \\
\hline - & - & - & - & - & - & OED-6 & 10 & 1 & 0.784 \\
\hline- & - & - & - & - & - & OED-7 & 10 & 1 & 0.784 \\
\hline- & - & - & - & - & - & OED-8 & 0 & - & 0.780 \\
\hline- & - & - & - & - & - & OED-9 & 0 & - & 0.795 \\
\hline - & - & - & - & - & - & OED-10 & 2 & 1 & 0.795 \\
\hline - & - & - & - & - & - & OED-11 & 5 & 1 & 0.795 \\
\hline - & - & - & - & - & - & OED-12 & 0 & - & 0.795 \\
\hline - & - & - & - & - & - & OED-13 & 2 & 2 & 0.780 \\
\hline - & - & - & - & - & - & OED-14 & 5 & 2 & 0.780 \\
\hline - & - & - & - & - & - & OED-15 & 13 & 1 & 0.795 \\
\hline - & - & - & - & - & - & OED-16 & 3 & 1 & 0.780 \\
\hline - & - & - & - & - & - & OED-17 & 5 & 1 & 0.780 \\
\hline - & - & - & - & - & - & OED-18 & 5 & 1 & 0.779 \\
\hline
\end{tabular}

$C S_{W}$, colloidal silica content; $e_{0}$, initial void ratio; ID, identification code; $\alpha$, ratio of accelerant to grout; $k_{10}$, hydraulic conductivity at $T=10^{\circ} \mathrm{C} ; k_{10}{ }^{*}$, hydraulic conductivity at $T=10^{\circ} \mathrm{C}$ after CS treatment; Method, specimen preparation procedure

was 0.3 , whereas it should be $\approx 0.5$ for materials that do not change their volume once loaded. Vranna and Tika (2019) reported that the compressibility of the CS solution (CS contents 6 and $10 \%$ ) prior to gelling, measured in the range of major interest for most liquefaction problems, $0-300 \mathrm{kPa}$, was $14-33$ (under a stress of $100 \mathrm{kPa}$ ) and $12-18$ (under a stress of $300 \mathrm{kPa}$ ) times greater than that of distilled and deaired water.

Before testing treated soil samples, the gel compressibility was analysed by preparing two pure CS gel specimens $\left(C S_{\mathrm{W}}=5\right.$ and $10 \%$, tested after one curing day underwater) inside a special stiff plexiglass ring ( $71 \mathrm{~mm}$ diameter, $18 \mathrm{~mm}$ height) with impervious bottom and side wall. An impervious plexiglass platen was placed on the top, which fitted snugly into the sample ring. The vertical compressive load was applied to the soil by means of a rigid metal cap placed above the plexiglass platen. In this way, undrained 1Dconfined compression tests on the pure gel were performed, and the observed strain was ascribed to the compressibility of the gel skeleton, being the water flow prevented by the impervious platen. During these tests, it was not possible to apply any loading sequence because both samples started to subside under the weight of the cap distributing the load, placed on the top platen, which transmitted a pressure of about $1.4 \mathrm{kPa}$. The results of these tests are shown in Figure 2. Therefore, even if a proper measurement of the silica gel compressibility was not possible, clear evidence of it was observed.

Confined 1D-compression tests (oedometer tests) were carried out on treated $\left(C S_{\mathrm{W}}=2,3,5,10\right.$ and 13\%) and untreated $\left(C S_{\mathrm{W}}=0 \%\right)$ sand samples. Untreated sand specimens were prepared by pluviating dry sand inside the oedometer steel ring to achieve the desired initial void ratio. Treated samples were formed following two different techniques: using the first method (grout pluviation, referred to as Method 1), dry sand was poured into the oedometer steel ring that was previously partly filled with an amount of CS grout equal to the calculated volume of voids. Method 1 was also used for the preparation of both cyclic triaxial and direct shear test specimens, as is apparent from the description of the preparation procedure described in 'Cyclic triaxial tests' and 'Direct shear tests' sections. Using the second method (grout permeation, referred to as Method 2), the dry sand was directly poured into the ring and then treated with CS grout poured by means of a syringe (not embedded) from the top of the specimens. The amount of grout used for gel saturation was equal to the calculated volume of voids. The two methods replicate

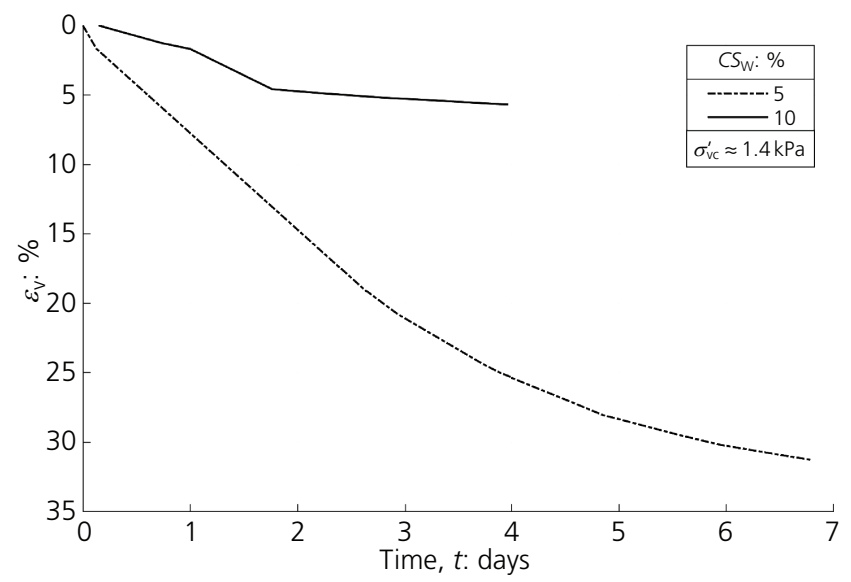

Figure 2. Undrained 1D-confined compression tests on pure CS gel samples 
those proposed by Georgiannou et al. (2017) (Method 1) and Wong et al. (2018) (Method 2), respectively. Georgiannou et al. (2017) showed that sand (M31 sand, $D_{50}=0.31 \mathrm{~mm}$ ) treated with $10 \%$ by weight silica content experienced more strain than untreated sand under 1D-confined compression tests; conversely, Wong et al. (2018) found opposite results for sand (Leighton Buzzard sand, $D_{50}=1.2 \mathrm{~mm}, U=1.26$ ) treated with $34 \% C S_{\mathrm{W}}$.

In this study, samples were formed on a plastic plate, and rings were sealed with silicon grease to avoid grout leakage. Each treated specimen was prepared outside the oedometer cell and, after gelation, was put directly into the oedometer chamber (without extrusion), with saturated porous stones and filter paper. The oedometer cell was filled with distilled water, and the specimen was left to cure. Loads were applied by steps from about $10 \mathrm{kPa}$ to about $1600 \mathrm{kPa}$ for the loading phase; each step was kept for at least $24 \mathrm{~h}$ even though most of the primary consolidation settlements were practically instantaneous, as shown in section headed 'Compressibility'. For the unloading phase, each step was kept for at least $24 \mathrm{~h}$, from approximately $1600 \mathrm{kPa}$ to about $10 \mathrm{kPa}$. The main details of the oedometer tests are provided in Table 2. Two specimens (17-OED and 18-OED, Method 1, $C S_{\mathrm{W}}=$ $5 \%$ ) were used to check the quality samples and to investigate the viscous effects. They were tested by applying just two subsequent loading steps: the first one (vertical effective pressure of $248 \mathrm{kPa}$ ) was kept for 1 week and the second one (vertical effective pressure of $496 \mathrm{kPa}$ ) for 30 days (without unloading phase).

\section{Results and discussion}

\section{Cyclic liquefaction resistance}

Figures 3(a)-3(d) show the results of cyclic triaxial tests on two loose (Figure 3(a), CTT-8; Figure 3(b), CTT-9) and two dense (Figure 3(c), CTT-1; Figure 3(d), CTT-4) untreated sand samples in the $p^{\prime}-q$ (top row), $\varepsilon_{\mathrm{q}}-q$ (middle row) and $N-r_{\mathrm{u}}$ (bottom row) planes, where $p^{\prime}$ and $\varepsilon_{\mathrm{q}}$ are the effective mean confining stress and the deviatoric strain, respectively. Each specimen is subjected to a different value of the normalised CSR (defined in 'Cyclic triaxial tests' section), and each one shows a different behaviour under cyclic loading: no failure for CTT-8 (CSR $=0.11$, Figure 3(a)), failure $\left(r_{\mathrm{u}}=\right.$ 1.0 at $N=77)$ for CTT-9 (CSR $=0.13$, Figure $3(\mathrm{~b}))$, failure $\left(\varepsilon_{\mathrm{DA}}=\right.$ $5 \%, r_{\mathrm{u}}<1.0$ at $\left.N=37.5\right)$ for CTT-1 (CSR $=0.20$, Figure 3(c)) and failure $\left(r_{\mathrm{u}}=1.0\right.$ at $\left.N=8\right)$ for CTT-4 (CSR $=0.27$, Figure 3(d)). As can be seen from the $\varepsilon_{\mathrm{q}}-q$ plot, the specimen in test CTT- 8 (Figure 3(a)) developed strain only in the positive side (compression). This is probably due to a small bedding error whose effects can be emphasised at very small strains (the maximum deviatoric strain reached during the test is approximately $0.06 \%$ ). It is worth saying that all the remaining untreated loose specimens tested in this study, which are not shown in Figure 3 (CTT-7, CTT-10 and CTT-11; see
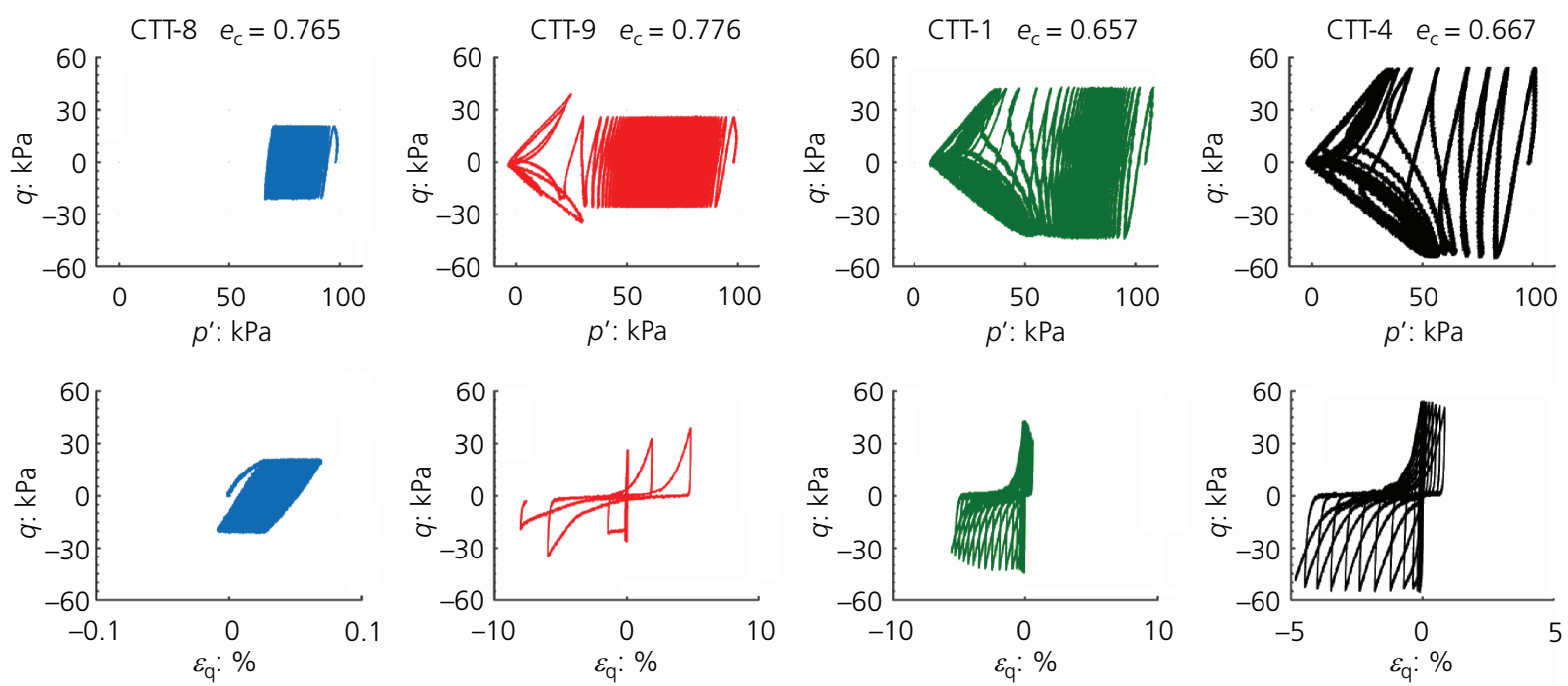

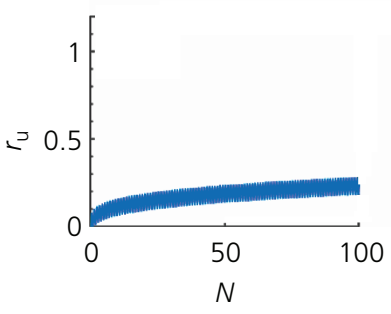

(a)

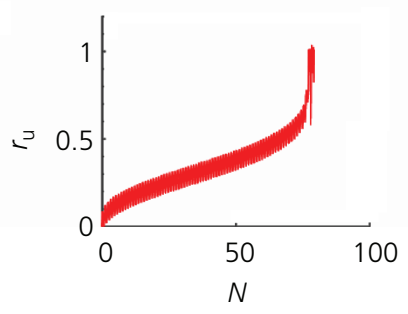

(b)

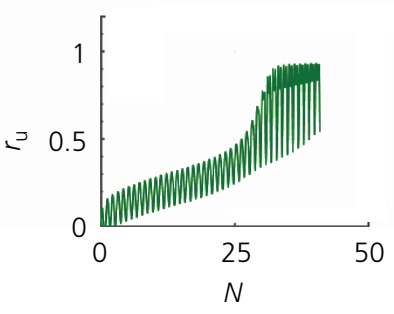

(c)

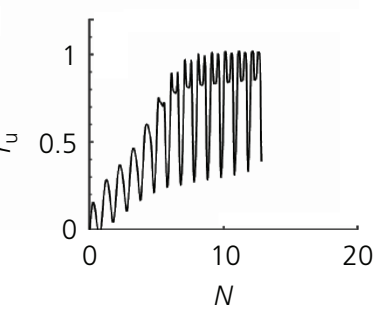

(d)

Figure 3. Cyclic triaxial test results on untreated loose and dense specimens: (a) CTT-8, (b) CTT-9, (c) CTT-1 and (d) CTT-4 

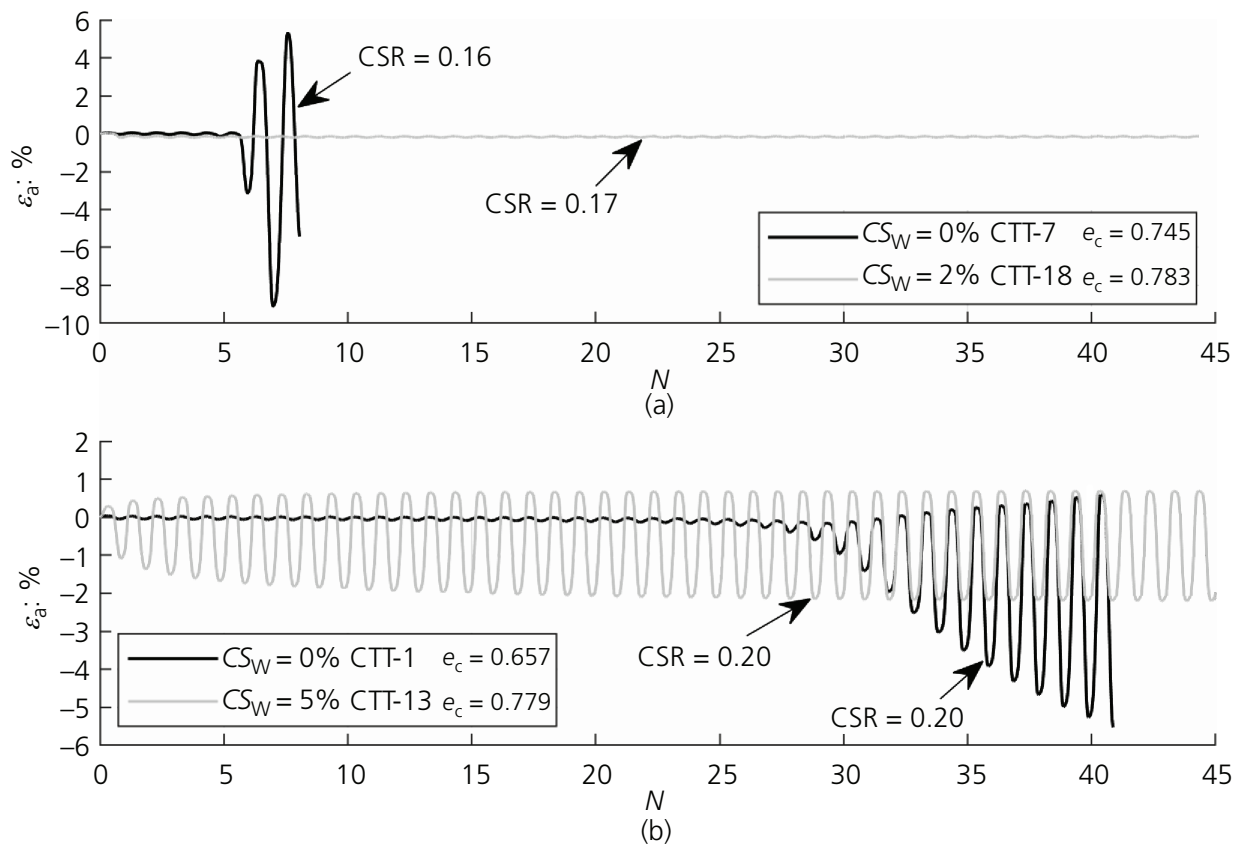

Figure 4. Axial strain plotted against the number of cycles for (a) loose untreated and treated sands and (b) dense untreated and loose treated sands

Table 1), showed a state of softening at failure like that exhibited by CTT-9 (Figure 3(b)). However, because the failure condition was not achieved in test CTT-8 (Table 1), the liquefaction resistance curve obtained for loose S3 sand was not affected by the result of this test. The different response curves for tests CTT- 8 and CTT-9 (Figures 3(a) and 3(b), respectively) are mostly ascribed to the different stress levels induced during the tests. The difference between the two imposed CSR values is not great (0.02), but it is enough to induce or not induce failure within 100 loading cycles. That is, failure was not reached in 100 cycles in test CTT-8 (Figure 3(a)), whereas it was reached in a very high number of loading cycles $(N=77)$ in test CTT-9 (Figure 3(b)). In test CTT-1 (Figure 3(c)), dense sand shows progressive plastic strain accumulation (cyclic mobility, $r_{\mathrm{u}}<1.0$ at failure), whereas during test CTT-4 (Figure 3(d)), a cyclic-mobilitylike behaviour (i.e. no flow deformation) is observed after the condition $r_{\mathrm{u}}=1.0$ (Castro, 1975).

A comparison between the deformation response of treated and untreated sands is provided in Figure 4. Axial strain against number of cycles is shown for loose untreated (CTT-7) and treated $\left(\mathrm{CTT}-18, C S_{\mathrm{W}}=2 \%\right.$ ) sand (Figure $4(\mathrm{a})$ ) and for loose treated (CTT-13, $C S_{\mathrm{W}}=5 \%$ ) and dense untreated sand (CTT-1) (Figure 4(b)). Figure 4(a) shows that, for a very similar CSR value, the treated sand specimen does not reach failure, whereas for the untreated one, the axial strain increases suddenly, and failure occurs after a few cycles, although the latter has a slightly smaller void ratio. Figure 4(b) shows that, for the same CSR value, the treated sand specimen does not reach failure, whereas for the untreated one, the axial strain develops with $N$, reaching failure for $N=37.5$, although the latter has a significantly smaller void ratio (dense sand). In Figure 4, it is worth noting that the axial strain for treated sand mainly develops towards extension, in agreement with observations made in previous research for weakly grouted sand (e.g. Gallagher and Mitchell 2002; Porcino et al., 2011).

Results from the cyclic triaxial tests are also represented in the $N$-CSR plane in Figure 5, which shows the experimental data obtained both from dense (CTT-1-CTT-6, Table 1) and loose (CTT-7-CTT-11, Table 1) untreated sand samples and from treated loose sand $\left(C S_{\mathrm{W}}=5 \%\right.$ and $C S_{\mathrm{W}}=2 \%$, tests CTT-12-CTT-17 and CTT-18-CTT-23 in Table 1, respectively). The best-fit lines CSR-N, which identify the liquefaction resistance curves for the four cases

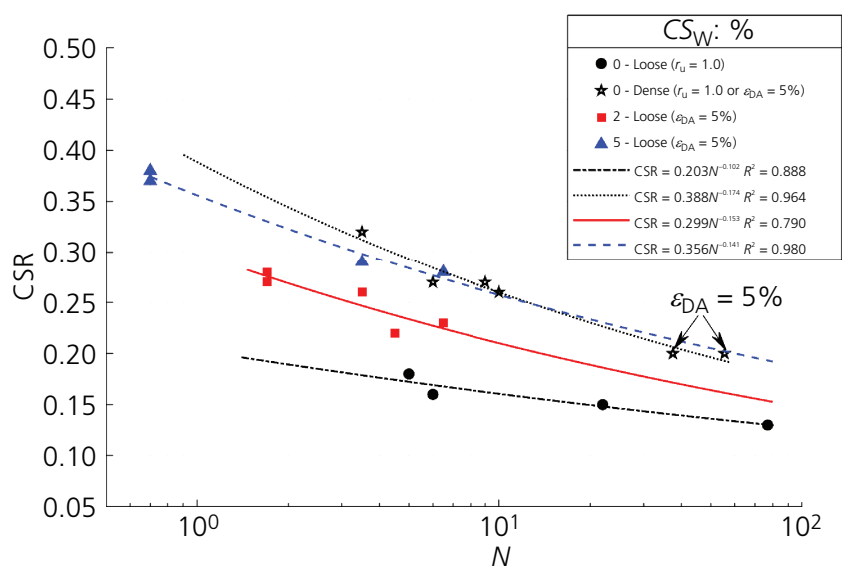

Figure 5. Cyclic resistance curves for treated and untreated materials 
Effects of high-diluted colloidal silica

grouting on the behaviour of liquefiable

sand

Ciardi, Bardotti, Vannucchi and Madiai

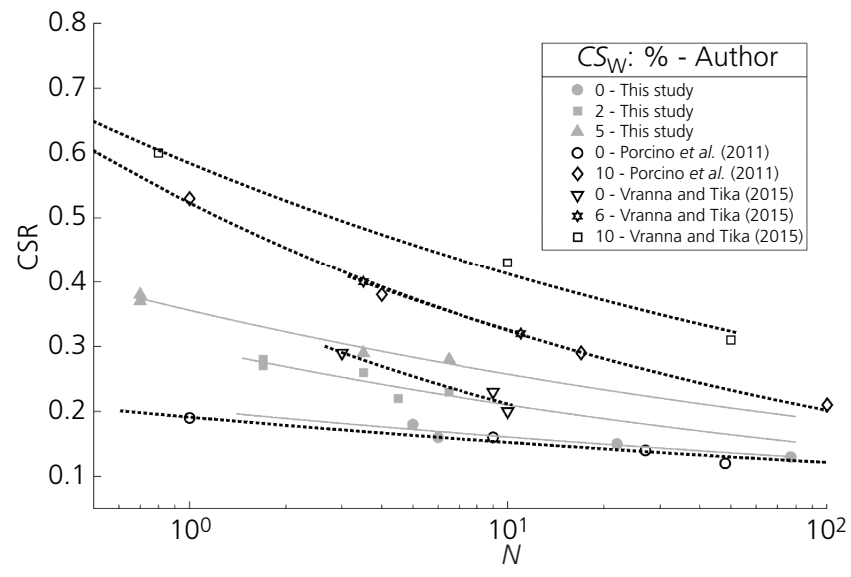

Figure 6. Comparison of cyclic resistance curves from different studies

considered, are also plotted in Figure 5. They are defined by the power function equations shown in the legend of Figure 5. As can be seen, the liquefaction resistance of loose sand increases with increasing $C S_{\mathrm{W}}$, and the liquefaction resistance of loose sand treated with $5 \% C S_{\mathrm{W}}$ is comparable with that of dense untreated material. In Figure 6, the liquefaction resistance curves obtained in this study for treated and untreated loose sand are compared with the results from undrained cyclic triaxial tests from previous studies (Porcino et al., 2011; Vranna and Tika, 2015). The comparison shows a good agreement in the experimental data trends, especially with the results obtained by Porcino et al. (2011) for uniform silica sand (Ticino sand). Moreover, the experimental data obtained in this study point out that $C S_{\mathrm{W}}=2 \%$ is suitable for improving soil behaviour under cyclic loading conditions, proving its effectiveness in liquefaction mitigation. Thus, a weak CS gel seems able to increase the liquefaction resistance of clean sand. The improvement factor $I_{\mathrm{f}}$, defined as $\mathrm{CSR}_{\text {treated }} / \mathrm{CSR}_{\text {untreated }}$ ratio according to Porcino et al. (2011), can be used to quantify the level of improvement in soil behaviour under cyclic loading conditions obtained after CS grouting.

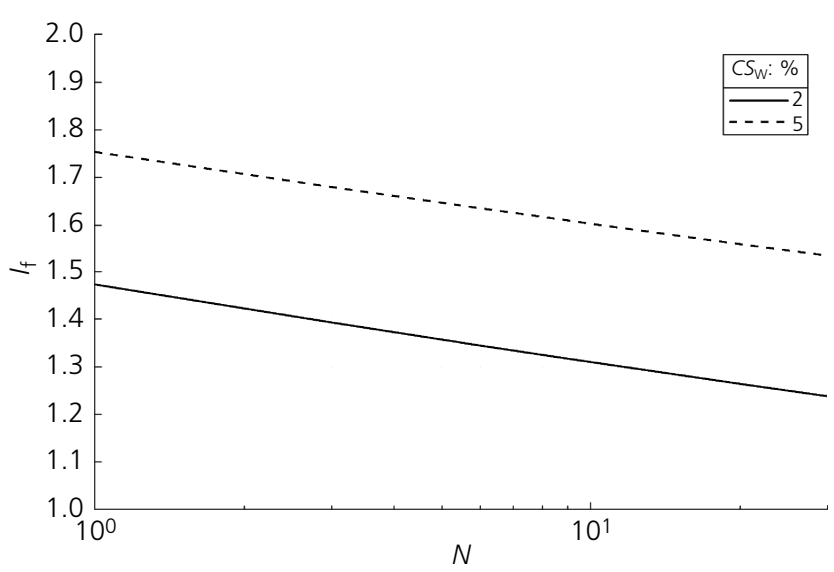

Figure 7. Improvement factor from cyclic triaxial tests
Figure 7 shows the improvement factor $I_{\mathrm{f}}$ against $N$ calculated with reference to the liquefaction resistance curves for $C S_{\mathrm{W}}=2 \%$ and $C S_{\mathrm{W}}=5 \%$ treated sand. As can be seen, $I_{\mathrm{f}}$ decreases with $N$, suggesting that the gel matrix progressively degrades with loading cycles. These data agree with those reported in Porcino et al. (2011). For $N=15$ and $C S_{\mathrm{W}}=2 \%$, however, $\mathrm{CSR}_{\text {treated }}$ is approximately $28 \%$ greater than $\mathrm{CSR}_{\text {untreated. }}$ For comparison with another innovative ground improvement technique, $I_{\mathrm{f}}$ calculated from cyclic direct simple shear tests on a moderately loose biocemented sand (data from Montoya et al., 2013) is approximately 3.8 for $N=15\left(I_{\mathrm{f}} \approx 1.58\right.$ for $C S_{\mathrm{W}}=5 \%$, Figure 7 , and $I_{\mathrm{f}} \approx 2.1$ for $C S_{\mathrm{W}}=10 \%$ from Porcino et al. (2011), for $N=15$ ).

\section{Strength parameters under static loading conditions}

In a previous work, Ciardi et al. (2019) showed that the peak shear stress at a failure of $2 \%$ CS grouted S3 sand in monotonic triaxial tests was higher than that of untreated sand, and it increased as effective confining pressure increases. Those results were interpreted, for treated sand, in terms of total stress because measurements of the pore water pressure were not available. In contrast, in this study, the results of direct shear tests are discussed in terms of effective stress. The stress-horizontal displacement relationships for both treated and untreated sands resulting from direct shear tests are reported in Figure 8, where $\tau$ is the shear stress and $S_{\mathrm{h}}$, the horizontal displacement. As can be seen, the peak stress for treated sand $\left(C S_{\mathrm{W}}=2 \%\right)$ is a little higher than that of the untreated one for the same effective vertical pressure $\sigma_{\mathrm{vc}}^{\prime}$.

To point out the effects on the volumetric response (contraction/ dilation), the vertical displacement $\left(S_{\mathrm{v}}\right)$ against the horizontal displacement is shown in Figure 9 for $\sigma_{\mathrm{vc}}^{\prime}=98,196$ and $294 \mathrm{kPa}$ for treated and untreated materials. Settlements $\left(S_{\mathrm{v}}\right)$ are assumed positive downwards. As can be observed in Figure 9, with reference to the same consolidation pressure, the treated material exhibits overall greater settlements than the untreated sand.

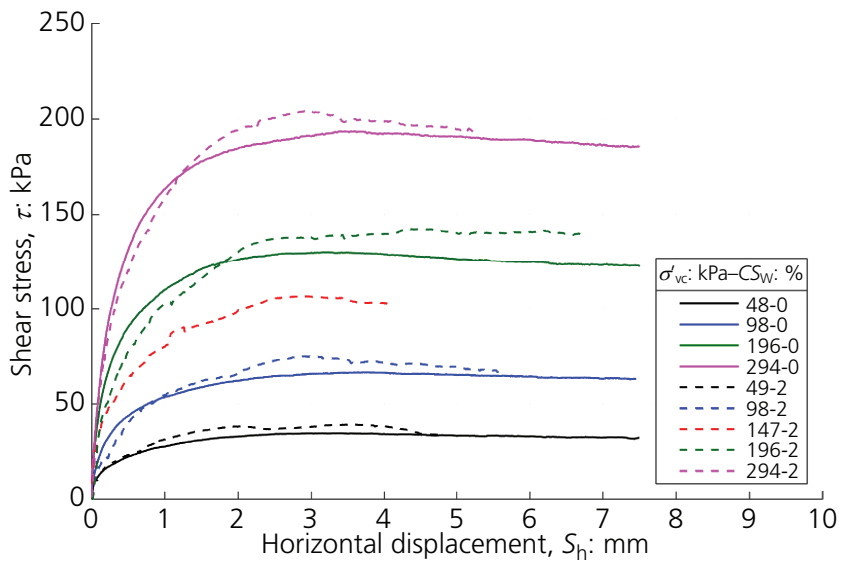

Figure 8. Stress to horizontal displacement curves from direct shear tests 
Effects of high-diluted colloidal silica

grouting on the behaviour of liquefiable

sand

Ciardi, Bardotti, Vannucchi and Madiai

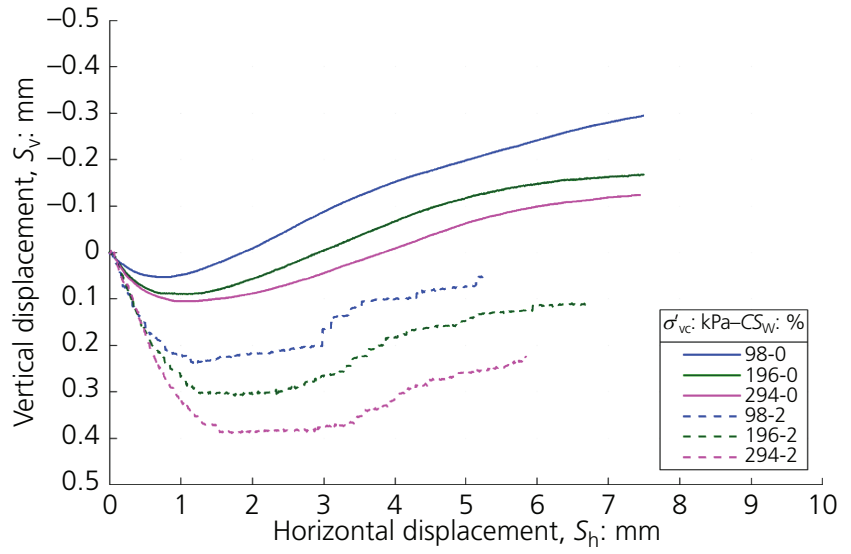

Figure 9. Vertical to horizontal displacement curves from direct shear tests

Contraction is significantly enhanced at the initial loading stage $\left(S_{\mathrm{h}}<1 \mathrm{~mm}\right)$. This is in agreement with the results from oedometer tests and could be ascribed to the gel compressibility ('1D-confined compression tests' section). Treated sand reaches the condition of zero-dilation at greater $S_{\mathrm{h}}$ values than the untreated one. This condition is maintained as $S_{\mathrm{h}}$ increases in quite a wide range $(\approx 1-3 \mathrm{~mm})$. This is much more evident as the effective vertical pressure increases. After that, dilation follows for treated and untreated sands. For untreated sand, there is a complete recovery of the initial specimens' height, together with an expansion (i.e. negative $S_{\mathrm{v}}$ ) at the end of each test. Similar results were previously obtained from monotonic drained triaxial tests on untreated S3 sand: Figure 10 (data from Ciardi et al.,
2019) shows the $\varepsilon_{\mathrm{a}}-q$ and $\varepsilon_{\mathrm{a}}-\varepsilon_{\mathrm{vol}}$ curves, where $\varepsilon_{\mathrm{vol}}$ is the volumetric strain. As shown in Figure 9, grouted sand samples do not recover the initial height (i.e. positive $S_{\mathrm{v}}$ ). The condition of maximum dilation is not significantly influenced by the presence of gel, and it is observed in the range $S_{\mathrm{h}} \approx 3-4 \mathrm{~mm}$ for both treated and untreated materials. Moreover, after the start of dilation, the trend of $S_{\mathrm{h}}-S_{\mathrm{v}}$ curves is similar for treated and untreated sands for a given value of $\sigma_{\mathrm{vc}}^{\prime}$. Ultimately, the effect of the gel on the contraction is greater than that induced on dilation. Previous studies have highlighted an enhanced dilatancy for $10 \%$ CS grouted sand (Porcino et al., 2012; Georgiannou et al., 2017); on the contrary, dilatancy is marginally affected by the CS treatment when $2 \% \mathrm{CS}$ mixture is used.

Failure envelopes for treated and untreated sands are reported in Figure 11; the peak angle of shearing resistance, $\phi^{\prime}$, and the effective cohesion, $c^{\prime}$, were determined from experimental data by means of a linear regression assuming a Mohr-Coulomb failure criterion for both materials. Values of $\phi^{\prime}=33.5^{\circ}$ and $c^{\prime}=0$ were obtained for the untreated sand, whereas $\phi^{\prime}=33.9^{\circ}$ and $c^{\prime}=8 \mathrm{kPa}$ were determined for treated sand. Values of $\phi^{\prime}=33.7^{\circ}$ and $c^{\prime}=0$ were obtained for untreated sand from the results of drained monotonic triaxial tests (Ciardi et al., 2019).

As can be seen in Figure 11, the CS gel filling the pore space provides a small cohesion to the soil, which is mainly responsible for the improvement in strength. On the other hand, $\phi$ is practically unaffected by the presence of gel. The slight increase from untreated to treated sand could be due to experimental uncertainties or to an increase in the roughness of the soil particles after the CS treatment, as it could be observed, for example, from microscopic images of CS

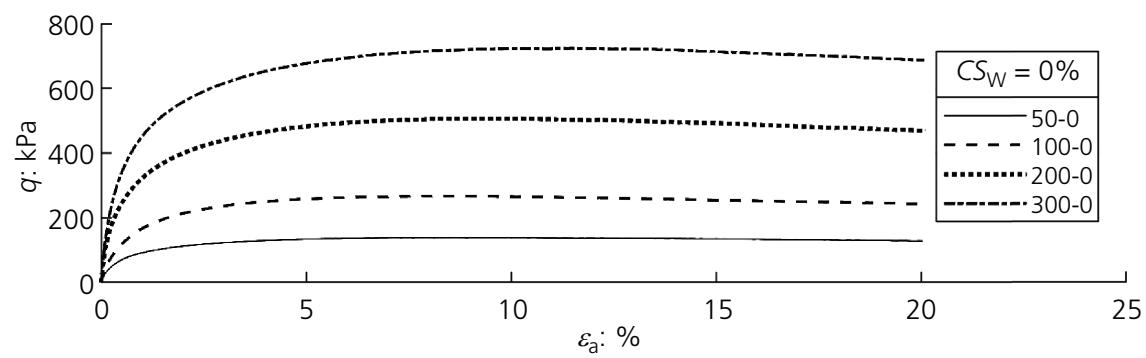

(a)

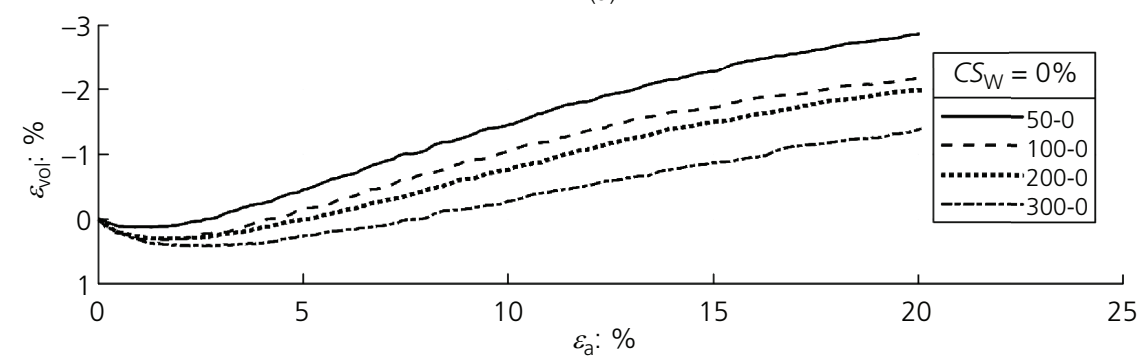

(b)

Figure 10. (a) Stress-strain and (b) volumetric response from drained monotonic triaxial tests on untreated S3 sand (data from Ciardi et al. (2019)) 
Effects of high-diluted colloidal silica

grouting on the behaviour of liquefiable

sand

Ciardi, Bardotti, Vannucchi and Madiai

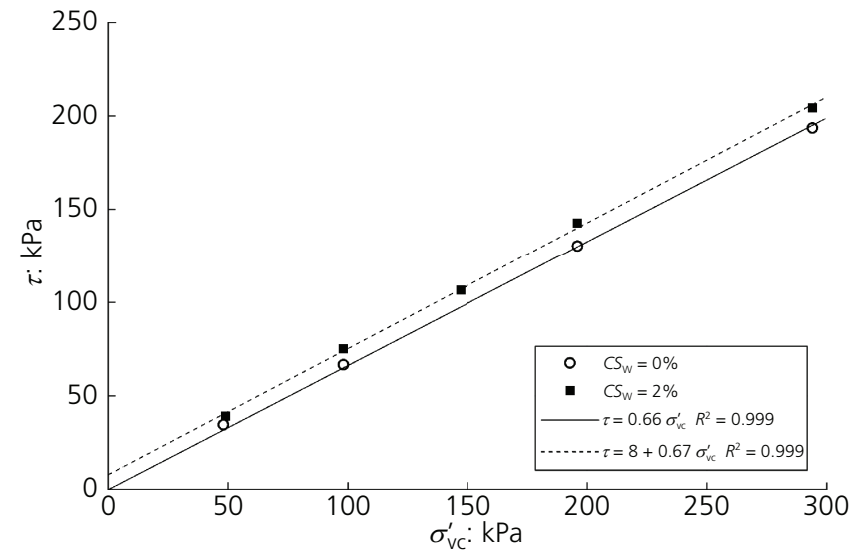

Figure 11. Failure envelopes for treated and untreated sands

treated materials (Porcino et al., 2012), or it could be a consequence of the small volume reduction observed during the early loading stage (Figure 9). The increase in $c^{\prime}$ and $\phi^{\prime}$ has also been observed in previous studies. Porcino et al. (2012) reported a 29-kPa increase in $c^{\prime}$ for Ticino sand treated with $10 \% C S_{\mathrm{W}}$ grout and a slight difference between the peak angle of shearing resistance for treated and untreated materials $\left(1^{\circ}\right)$ from drained monotonic triaxial tests; Wong et al. (2018) measured a $26-\mathrm{kPa}$ increase in $c^{\prime}$ for $34 \% C S_{\mathrm{W}}$ grouted Leighton Buzzard sand and an $8^{\circ}$ difference between the peak angles from direct shear tests. From direct shear tests on medium-dense sand (M31 sand) $\left(c^{\prime}=0 \mathrm{kPa} ; \phi^{\prime}=32.5^{\circ}\right.$ for untreated material) treated with $10 \% C S_{\mathrm{W}}$, Georgiannou et al. (2017) assumed a curved failure envelope $\left(c^{\prime}=0 \mathrm{kPa} ; \phi^{\prime}=41.3^{\circ}\right.$ at vertical effective stress $\sigma_{\mathrm{v}}^{\prime}=125 \mathrm{kPa}$ and $\phi=34.9^{\circ}$ at $\sigma_{\mathrm{v}}^{\prime}=555 \mathrm{kPa}$ ); from drained triaxial tests on material treated with the same $10 \% C S_{\mathrm{W}}$, they obtained $c^{\prime}=14 \mathrm{kPa}$ and $\phi^{\prime}=38.3^{\circ}-35^{\circ}$ at effective confining pressure in the range $100-700 \mathrm{kPa}$. For comparison with another emerging technique, the peak friction angle and cohesion of biocemented soil are expected to increase with increasing percentage of precipitated calcite: for instance, based on data shown by Cui et al. (2017) from triaxial tests on loose sand, an increase in $\phi^{\prime}$ of $\approx 1.7^{\circ}$ and in $c^{\prime}$ of $\approx 33 \mathrm{kPa}$ is obtained for $2 \%$ calcite content. These values are much farther from those obtained for $2 \%$ CS grouted sand.

\section{Hydraulic conductivity}

Results from hydraulic conductivity tests are listed in Table 2 and represented in Figure 12, where $e$ is the void ratio and $k_{10}$, the hydraulic conductivity at $10^{\circ} \mathrm{C}$, respectively. The hydraulic conductivity values measured for untreated sand are in agreement with those of medium-fine sand with a void ratio $e=0.6-0.8$ and an average grain size $D_{50}=0.1-0.5 \mathrm{~mm}$ (Karol, 2003). A $10^{4}$-fold $\left(10^{5}\right.$-fold) decrease was observed for $2 \%(5 \%) C S_{\mathrm{W}}$ grouted material. It is worth noting that the amplitude of $k_{10}$ reduction for treated sand was not significantly affected by the amount of grout passed throughout the specimens: specimens treated with approximately three pore volumes of grout or by much more stabilising agent exhibited similar $k_{10}$ values, suggesting that even

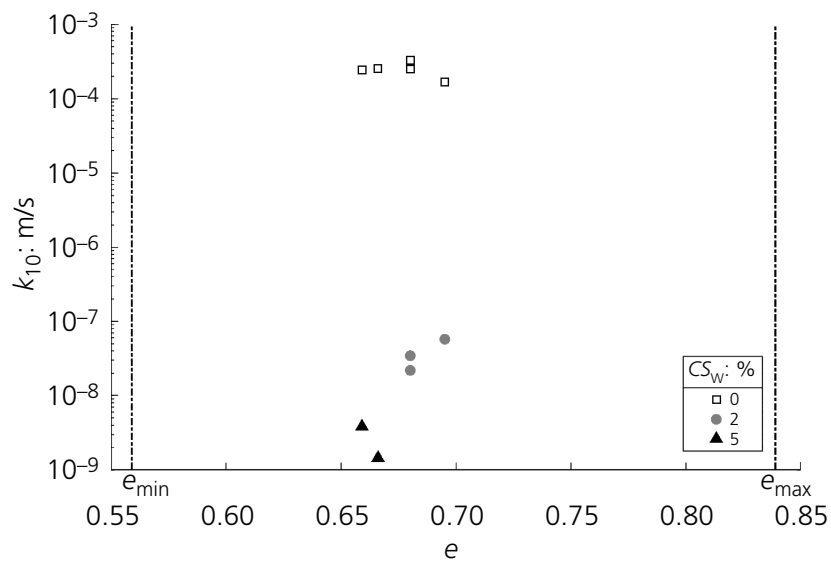

Figure 12. Hydraulic conductivity measurements on treated and untreated materials

if the soil is not completely saturated with gel, a drastic $k$ reduction is also expected after CS treatment with high-diluted CS mixtures. Although hydraulic conductivity measurements on sand grouted with high-diluted CS mixtures are not available in the literature, some comparisons with previous studies can be made. Persoff et al. (1999) found that the hydraulic conductivity for 5\% grouted Monterey \#0/30 sand was approximately $5 \times 10^{-9} \mathrm{~m} / \mathrm{s}$ and about $8 \times 10^{-10} \mathrm{~m} / \mathrm{s}$ for a different soil treated with the same $C S_{\mathrm{W}}$ (averaged values), and it was of the order of $10^{-11} \mathrm{~m} / \mathrm{s}$ for $27 \%$ $C S_{\mathrm{W}}$ grout; Porcino et al. (2012) found $k$ values of the order of $10^{-9} \mathrm{~m} / \mathrm{s}$ for Ticino sand treated with $10 \% C S_{\mathrm{W}}$ grout, whereas a drastic $k$ reduction was also detected by Wong et al. (2018), who showed a $10^{8}$ fold decrease of the hydraulic conductivity of treated sand $\left(C S_{\mathrm{W}}=34 \%\right)$ compared with the untreated one.

\section{Compressibility}

Results of oedometer tests are presented, making a distinction between loading and unloading phases. A summary plot of test results is shown in Figure 13 for the loading phase in terms of vertical strain $\varepsilon_{\mathrm{v}}$ (positive strain for compression) against the vertical effective stress normalised to the atmospheric pressure, $\sigma_{\mathrm{vc}}^{\prime} / p_{\mathrm{a}}$. For each test, the first loading step $\left(\sigma_{\mathrm{vc}}^{\prime}=10-12 \mathrm{kPa}\right)$ was assumed as an adjustment phase. Therefore, the first experimental point, $\sigma_{\mathrm{vc}}^{\prime} / p_{\mathrm{a}}-\varepsilon_{\mathrm{v}}$, was assumed as point $(0,0)$ in Figure 13. As can be seen, data are very well fitted by a hyperbolic function of Equation 1:

$$
\text { 1. } \varepsilon_{v}=\frac{\sigma_{v c}^{\prime} / p_{a}}{a \sigma_{v c}^{\prime} / p_{a}+b}
$$

where $a$ and $b$ are the best-fit parameters. The values of $a$ and $b$ and the coefficient of determination $\left(R^{2}\right)$ are synthesised in Table 3 for the different $C S_{\mathrm{W}}$.

As can be seen in Figure 13, regardless of the used specimen preparation procedure ('1D-confined compression tests' section), the 

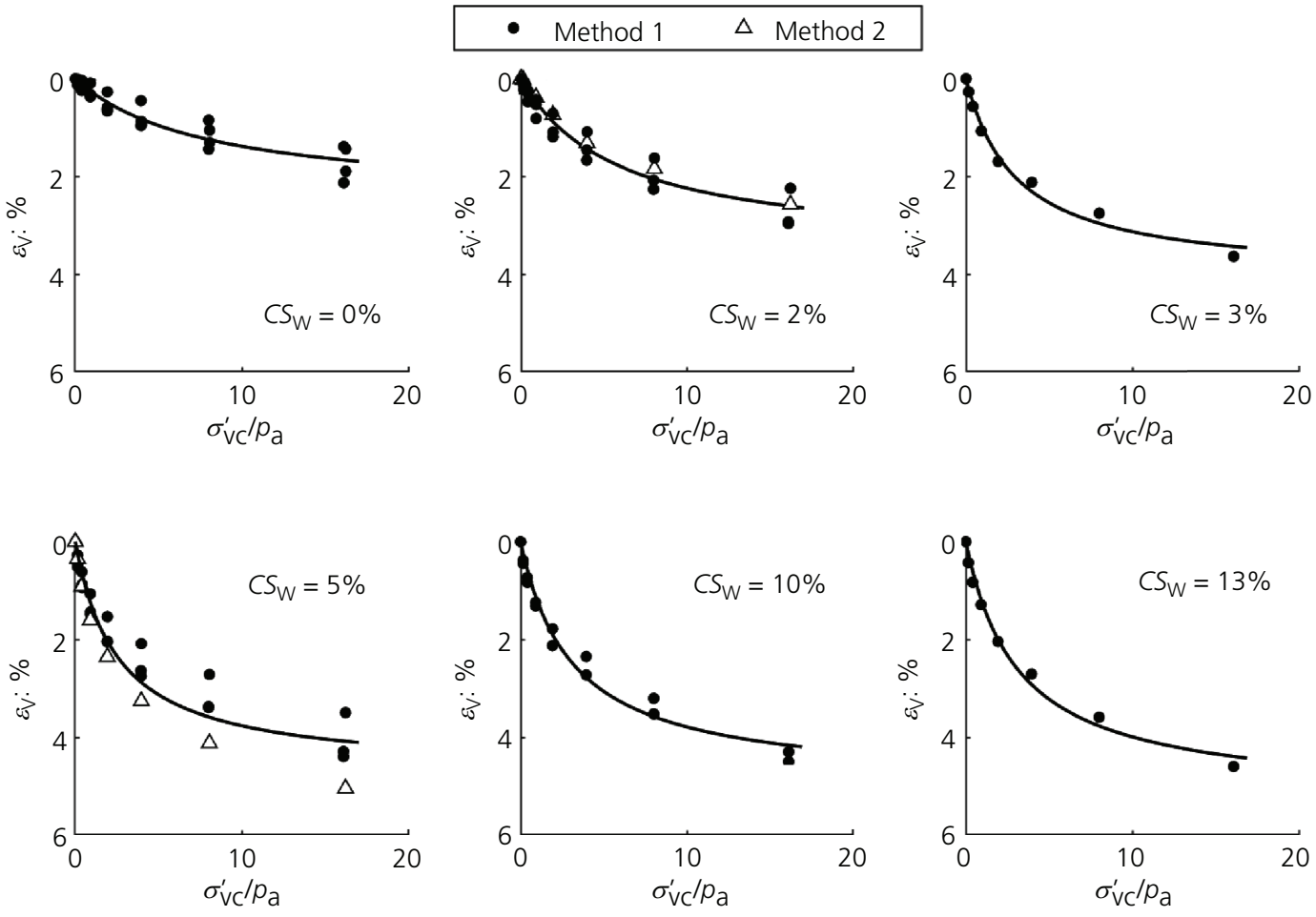

Figure 13. Loading phase from 1D-confined compression tests

treated sand is more compressible than the untreated one, and the difference between the volumetric strain for treated and untreated materials increases as $C S_{\mathrm{W}}$ increases for a given stress range (Figure 14). For $C S_{\mathrm{W}}>5 \%$, however, the stress-strain curves of treated sand are comparable with that of $5 \%$ grouted material, suggesting that as $C S_{\mathrm{W}}$ increases, the effect of gel compressibility on the overall compressibility of treated material is progressively counterbalanced by a more stable and stiff gel structure. The minor strain is recorded for $C S_{\mathrm{W}}=2 \%$. An increase in treated soil compressibility (for $C S_{\mathrm{W}}=$ $10 \%$ ) has also been reported by Georgiannou et al. (2017); however, these results disagree with data from Wong et al. (2018) that show a compressibility of treated sand $\left(C S_{\mathrm{W}}=34 \%\right)$ lower than those of the untreated one. According to Georgiannou et al. (2017), it can be argued that the pore gel acts as a sort of buffer among sand particles, facilitating the grain rearrangement. The opposite experimental findings of Wong et al. (2018) could have an explanation in the very high $C S_{\mathrm{W}}$ they adopted for soil grouting, which can cause significant

Table 3. Regression parameters

\begin{tabular}{|c|c|c|c|c|c|c|}
\hline \multirow{2}{*}{$C S_{w}: \%$} & \multicolumn{3}{|c|}{ Hyperbolic regression } & \multicolumn{3}{|c|}{ Logarithmic regression } \\
\hline & $a$ & $b$ & $R^{2}$ & c & $d$ & $R^{2}$ \\
\hline 0 & 0.402 & 3.199 & 0.906 & 0.250 & 0.596 & 0.851 \\
\hline 2 & 0.282 & 1.641 & 0.953 & 0.225 & 1.496 & 0.836 \\
\hline 3 & 0.245 & 0.740 & 0.986 & 0.309 & 2.656 & 0.942 \\
\hline 5 & 0.212 & 0.537 & 0.940 & 0.271 & 2.647 & 0.902 \\
\hline 10 & 0.201 & 0.625 & 0.978 & 0.313 & 3.331 & 0.952 \\
\hline 13 & 0.190 & 0.597 & 0.988 & 0.313 & 3.689 & 0.994 \\
\hline
\end{tabular}

differences in the final structure of treated material. Moreover, there seems to be a threshold in silica dilution above which the tendency in compressibility increase is reduced (Figure 14); this aspect needs further investigations. However, increasing $C S_{\mathrm{W}}$ to reduce settlements is in contrast with the idea of maximising the benefits of CS treatment minimising its economic cost.

Results for the unloading phase are shown in Figure 15, where vertical strain is plotted against the normalised vertical effective

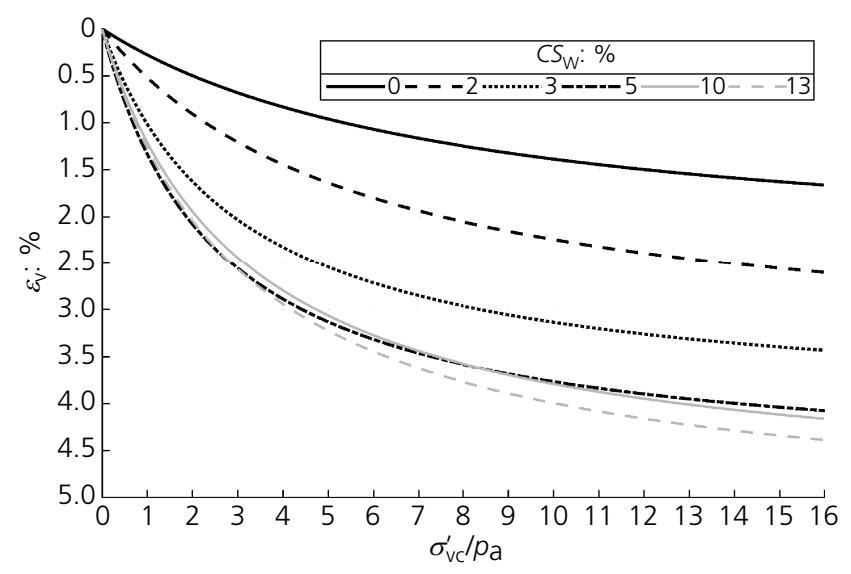

Figure 14. Hyperbolic regression curves from experimental data at different CS contents 

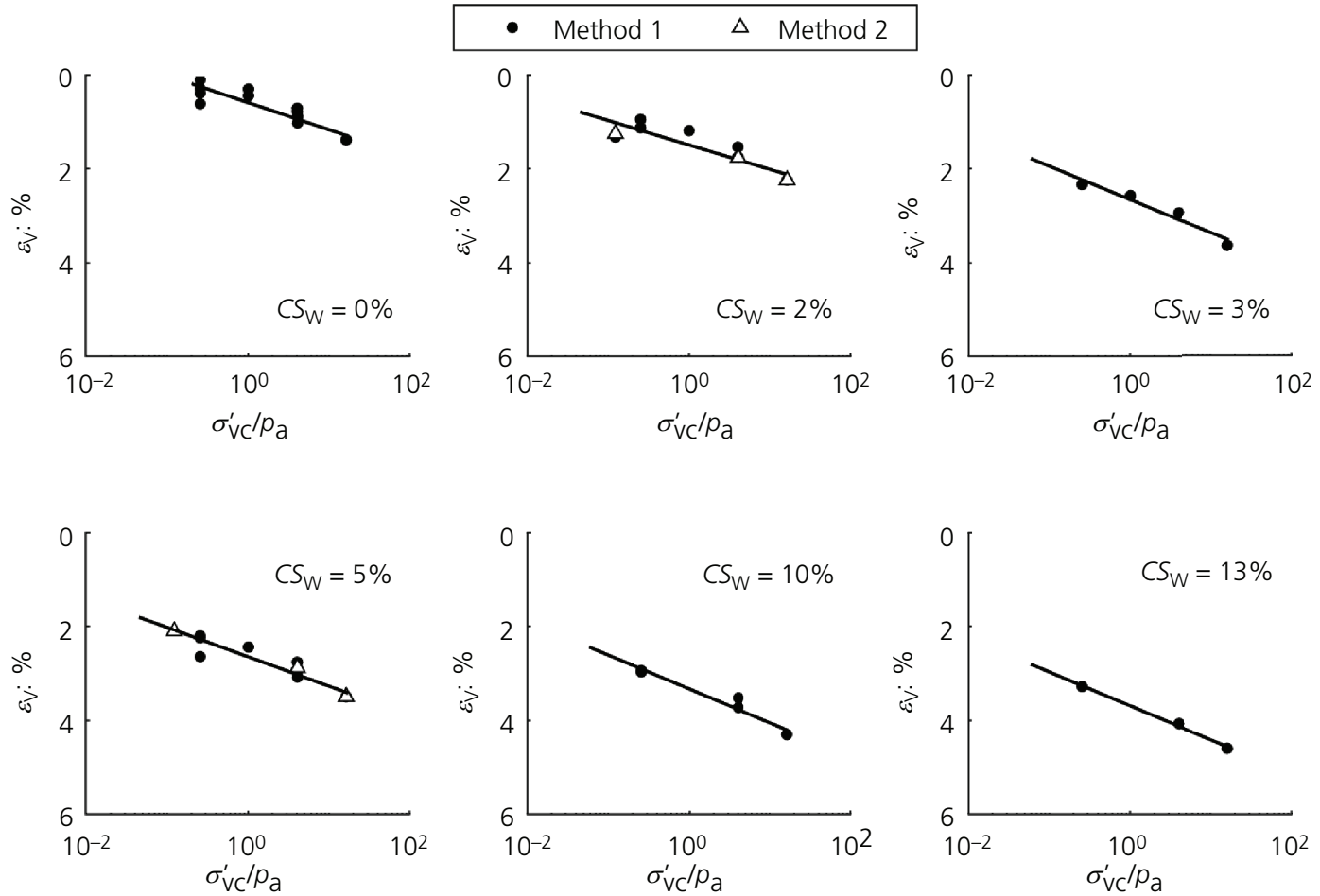

Figure 15. Unloading phase from 1D-confined compression tests

pressure (log-scale). For a given value of $C S_{\mathrm{W}}$, all the point data of each test were shifted of the same quantity on the $\varepsilon_{\mathrm{v}}$ axis so that all the unloading paths have the same initial point (namely, the minimum $\varepsilon_{\mathrm{v}}$ at the $\sigma_{\mathrm{vc}}^{\prime} / p_{\mathrm{a}}$ maximum value). Data are well fitted by Equation 2:

2. $\varepsilon_{v}=c \ln \left(\sigma_{v c}^{\prime} / p_{a}\right)+d$

where $c$ and $d$ are the linear model parameters. The values of $c$ and $d$ and the coefficient of determination $\left(R^{2}\right)$ are synthesised in Table 3 for the different $C S_{\mathrm{W}}$. As can be seen in Figure 15, the slope of the regression line is almost independent from $C S_{\mathrm{W}}$. It ranges from 0.23 to 0.31 and is equal to 0.25 for the clean sand (Table 3). This means that the elastic strain recovery during unloading is mainly governed by the response of the soil skeleton; on the other hand, the behaviour of the treated soil is markedly $C S_{\mathrm{W}}$ dependent, and the plastic strain developed during loading is governed by the amount of silica diluted in the stabilising grout (Figure 13).

Finally, the results of the tests performed on specimens OED-17 and OED-18 (Table 2), which were used to check the sample quality and to investigate the viscous effects, are synthesised in Figures 16 and 17. Both specimens were prepared by the grout pluviation method (defined as Method 1 in ' $1 \mathrm{D}$-confined compression tests' section), with $C S_{\mathrm{W}}=5 \%$ and initial void ratio $e_{0}=0.78$. As can be seen in Figure 16, they essentially showed the same vertical deformation over time when subjected to the same effective vertical pressure, which means that Method 1 allowed the preparation of good quality samples, enhancing the reproducibility of the same initial conditions for all tests. Furthermore, most of the developed strain is practically instantaneous. Figure 17 shows the vertical strain of OED-17 and OED-18 specimens subjected to a vertical load of $248 \mathrm{kPa}$ for 7 days and then to a vertical load of $496 \mathrm{kPa}$ for 30 days. Because the vertical strain developed over time is very small (for instance, vertical strain increases of about $0.15 \%$ in 29 days for both

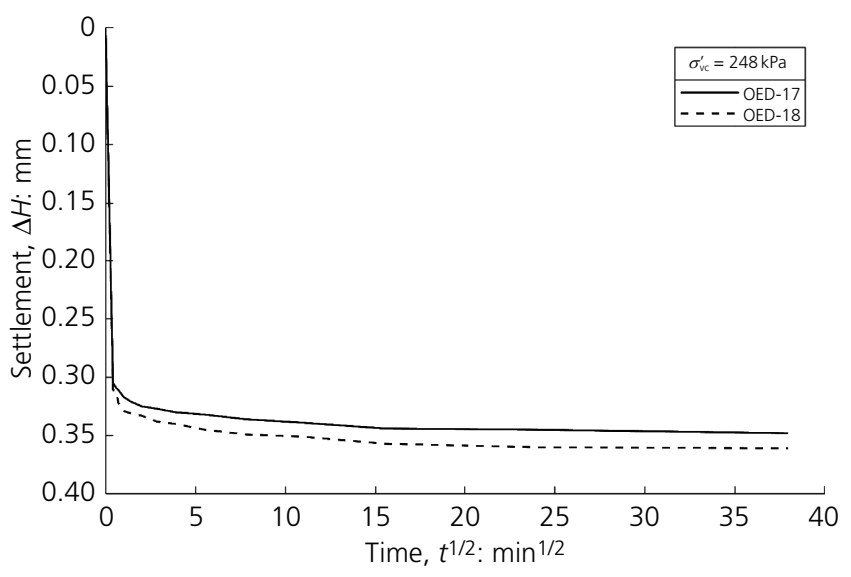

Figure 16. Settlement-time curves (square root of time scale) over $24 \mathrm{~h}$ for treated sand samples from oedometer tests 


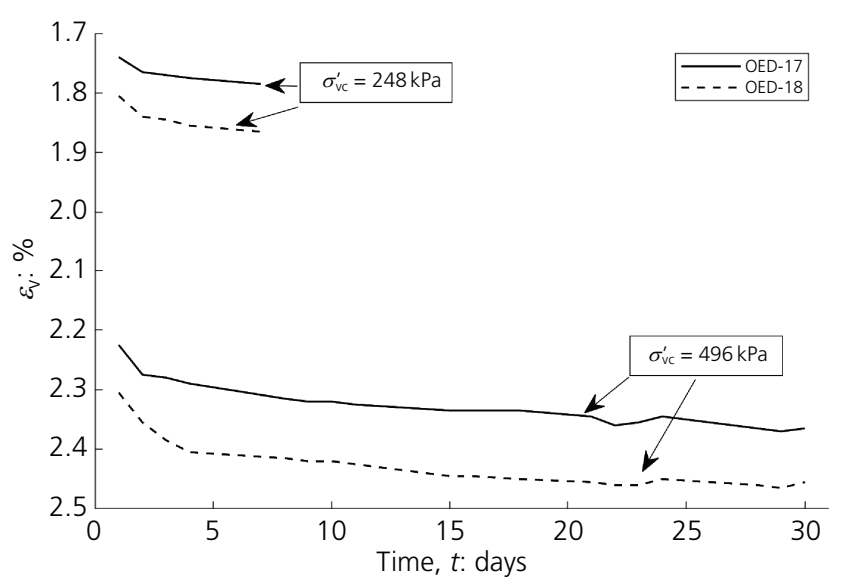

Figure 17. Deformation-time curves (linear time scale) over 7 and 30 days for treated sand samples from oedometer tests at two different loading steps

specimens subjected to $\sigma_{\mathrm{vc}}^{\prime}=496 \mathrm{kPa}$ ), the viscous component of the vertical deformation is negligible.

\section{Summary and conclusions}

An experimental laboratory campaign was performed to analyse all the main effects of treatment with high-diluted CS mixtures (CS < $5 \%$ by weight) on a clean liquefiable sand. First, the effectiveness of treatment on the soil liquefaction resistance was proven by cyclic triaxial tests. The effects on the strength parameters under static loading conditions were then evaluated by means of direct shear tests. Hydraulic conductivity measurements were carried out by means of falling head tests, and confined 1D-compression tests were performed to analyse the soil compressibility. Despite the latter's possible important implications for practical applications, it has been little addressed in the literature, and the results available to date are quite controversial.

On the basis of the results achieved, some conclusions can be drawn as follows.

- $2 \% C S_{\mathrm{W}}$ grout is effective in seismic liquefaction mitigation.

The presence of a 'weak' gel filling the pores improves soil performance under cyclic loading conditions, as observed in cyclic triaxial tests. The cyclic resistance of treated sand increases with increasing $C S_{\mathrm{W}}$. An improvement factor $I_{\mathrm{f}}$, defined as the ratio between the CSR causing failure in the treated material $\left(\mathrm{CSR}_{\text {treated }}\right)$ in a given number of uniform load cycles $N$ and the CSR causing failure in the untreated material $\left(\mathrm{CSR}_{\text {untreated }}\right)$ in the same number of $N$ cycles, can be used to quantify the increase in cyclic resistance. For the tested sand, an increase of about $28 \%$ was obtained for $N=$ 15 with $C S_{\mathrm{W}}=2 \%$.

- Direct shear tests carried out in drained conditions showed that $2 \% C S_{\mathrm{W}}$ grout provides the treated material with a small cohesion (approximately $8 \mathrm{kPa}$ for the sand tested in this study) responsible for the soil strength increase under static loading conditions. The dilatancy is less affected by the presence of $2 \% \mathrm{CS}$ gel than the volume reduction observed at the early loading stage of each test. The peak angle of shearing resistance has been observed to be practically unaffected by the presence of this high-diluted silica gel.

- Measurements from permeability tests revealed that the hydraulic conductivity decreases, for treated sand, as $C S_{\mathrm{W}}$ increases and that even $2 \% C S_{\mathrm{W}}$ grouting causes a significant decrease in water flow rate. For the tested medium-dense sand, $10^{4}$ - and $10^{5}$-fold decrease was observed, respectively, for $2 \%$ and $5 \% C S_{\mathrm{W}}$ grout.

- Confined 1D-compression tests carried out to investigate the compressibility of treated and untreated materials pointed out that the treated sand is more compressible than the untreated one. This result was obtained from all the tests performed under different initial and boundary test conditions. However, the compressibility of samples treated with $C S_{\mathrm{W}}>5 \%$ grouts was found to be comparable with that of sand treated with $C S_{\mathrm{W}}=5 \%$ mixtures, suggesting that this negative effect does not significantly further increase as the silica solids percentage increases above a given threshold. The existence of this threshold, however, may be characteristic of the specific set of data used in this study, and this needs further investigations.

In conclusion, in view of practical application to reduce seismic soil liquefaction hazard, high-diluted CS grouting is advisable because it allows minimising the negative effects induced by CS gel on the compressibility of the treated material. From this study, $C S_{\mathrm{W}}=2 \%$ seems able to improve the behaviour of liquefiable material under seismic and static loading conditions, inducing a moderate increase of its compressibility.

\section{Acknowledgement}

This work was partially supported by DPC-ReLUIS Research Project 2019.

\section{REFERENCES}

Agapoulaki GI and Papadimitriou AG (2018) Rheological properties of colloidal silica grout for passive stabilization against liquefaction. Journal of Materials in Civil Engineering 30(10): article 4018251.

Bao X, Jin Z, Cui H, Chen X and Xie X (2019) Soil liquefaction mitigation in geotechnical engineering: an overview of recently developed methods. Soil Dynamics and Earthquake Engineering 120: 273-291.

Bolisetti T, Reitsma S and Balachandar R (2009) Experimental investigations of colloidal silica grouting in porous media. Journal of Geotechnical and Geoenvironmental Engineering 135(5): 697-700.

Castro G (1975) Liquefaction and cyclic mobility of saturated sands. Journal of Geotechnical and Geoenvironmental Engineering 101(GT6): 551-569.

Ciardi G, Bardotti R, Vannucchi G and Madiai C (2019) Effects of highdiluted colloidal silica grout on the mechanical behavior of a liquefiable sand. In Proceedings of the 7th International Conference on Earthquake Geotechnical Engineering (Silvestri F and Moraci N (eds)). CRC Press, Boca Raton, FL, USA, pp. 1820-1827.

Conlee CT, Gallagher PM, Boulanger RW and Kamai R (2012) Centrifuge modeling for liquefaction mitigation using colloidal silica stabilizer. Journal of Geotechnical and Geoenvironmental Engineering 138(11): 1334-1345. 
Cui M, Zheng JJ, Zhang RJ, Lai H and Zhang J (2017) Influence of cementation level on the strength behaviour of bio-cemented sand. Acta Geotechnica 12(5): 971-986.

DeJong JT, Fritzges MB and Nüsslein K (2006) Microbially induced cementation to control sand response to undrained shear. Journal of Geotechnical and Geoenvironmental Engineering 132(11): 1381-1392.

Díaz-Rodríguez JA, Antonio-Izarraras VM, Bandini P and López-Molina JA (2008) Cyclic strength of a natural liquefiable sand stabilized with colloidal silica grout. Canadian Geotechnical Journal 45(10): $1345-1355$.

DIN (Deutsches Institut für Normung e.V.) (1996) DIN 18126: Soil, investigation and testing - determination of density of non-cohesive soils for maximum and minimum compactness. DIN, Berlin, Germany (in German).

El Mohtar CS, Bobet A, Santagata MC, Drnevich VP and Johnston CT (2013) Liquefaction mitigation using bentonite suspensions. Journal of Geotechnical and Geoenvironmental Engineering 139(8): 1369-1380.

Eseller-Bayat E, Yegian MK, Alshawabkeh A and Gokyer S (2012) Liquefaction response of partially saturated sands. I: Experimental results. Journal of Geotechnical and Geoenvironmental Engineering 139(6): 863-871.

Gallagher PM and Finsterle S (2004) Physical and numerical model of colloidal silica injection for passive site stabilization. Vadose Zone Journal 3(3): 917-925.

Gallagher PM and Lin Y (2009) Colloidal silica transport through liquefiable porous media. Journal of Geotechnical and Geoenvironmental Engineering 135(11): 1702-1712.

Gallagher PM and Mitchell JK (2002) Influence of colloidal silica grout on liquefaction potential and cyclic undrained behavior of loose sand. Soil Dynamics and Earthquake Engineering 22(9-12): 1017-1026.

Gallagher PM, Conlee CT and Rollins KM (2007a) Full-scale field testing of colloidal silica grouting for mitigation of liquefaction risk. Journal of Geotechnical and Geoenvironmental Engineering 133(2): 186-196.

Gallagher PM, Pamuk A and Abdoun T (2007b) Stabilization of liquefiable soils using colloidal silica grout. Journal of Materials in Civil Engineering 19(1): 33-40.

Georgiannou VN, Pavlopoulou EM and Bikos Z (2017) Mechanical behaviour of sand stabilised with colloidal silica. Geotechnical Research 4(1): 1-11, https://doi.org/10.1680/jgere.16.00017.

Hamderi M and Gallagher PM (2013) An optimization study on the delivery distance of colloidal silica. Scientific Research and Essays 8(27): 1314-1323.

Hamderi M and Gallagher PM (2015) Pilot-scale modeling of colloidal silica delivery to liquefiable sands. Soils and Foundations 55(1): $143-153$.

He J, Chu J and Ivanov V (2013) Mitigation of liquefaction of saturated sand using biogas. Géotechnique 63(4): 267-275.

Huang Y and Wang L (2016) Experimental studies on nanomaterials for soil improvement: a review. Environmental Earth Sciences 75(6): 496-510.

Huang $Y$ and Wen Z (2015) Recent developments of soil improvement methods for seismic liquefaction mitigation. Natural Hazards 76(3): 1927-1938

Iler RK (1979) The Chemistry of Silica: Solubility, Polymerization, Colloid and Surface Properties and Biochemistry of Silica. John Wiley and Sons Inc, New York, NY, USA.

Ishihara K (1993) Liquefaction and flow failure during earthquakes. Géotechnique 43(3): 351-415.

ISO (International Organization for Standardization) (2019) EN ISO 17892-11:2019. Geotechnical investigation and testing - laboratory testing of soil. Part 11: permeability tests. ISO, Geneva, Switzerland.

Karol RH (2003) Chemical Grouting And Soil Stabilization, Revised and Expanded. CRC Press, Boca Raton, FL, USA.
Kodaka T, Ohno Y and Takyu T (2005) Cyclic shear characteristics of treated sand with colloidal silica grout. In Proceedings of the International Conference on Soil Mechanics and Geotechnical Engineering. Balkema, Rotterdam, the Netherlands, vol. 16, pp. 401-404.

Mashiri MS, Vinod JS and Sheikh MN (2015) Liquefaction potential and dynamic properties of sand-tyre chip (STCh) mixtures. Geotechnical Testing Journal 39(1): 69-79.

Mollamahmutoglu M and Yilmaz Y (2010) Pre- and post-cyclic loading strength of silica-grouted sand. Proceedings of the Institution of Civil Engineers - Geotechnical Engineering 163(6): 343-348.

Montoya BM, DeJong JT and Boulanger RW (2013) Dynamic response of liquefiable sand improved by microbial-induced calcite precipitation. Géotechnique 63(4): 302-312.

Nouri Delavar I and Noorzad R (2020) Drained shear strength parameters of silty sand grouted by colloidal silica. International Journal of Geotechnical Engineering 14(1): 1-8.

Okamura M, Ishihara M and Tamura K (2006) Degree of saturation and liquefaction resistances of sand improved with sand compaction pile. Journal of Geotechnical and Geoenvironmental Engineering 132(2): 258-264.

Okamura M, Takebayashi M, Nishida K et al. (2011) In-situ desaturation test by air injection and its evaluation through field monitoring and multiphase flow simulation. Journal of Geotechnical and Geoenvironmental Engineering 137(7): 643-652.

Persoff P, Apps J, Moridis G and Whang JM (1999) Effect of dilution and contaminants on sand grouted with colloidal silica. Journal of Geotechnical and Geoenvironmental Engineering 125(6): 461-469.

Porcino D, Marcianò V and Granata R (2011) Undrained cyclic response of a silicate-grouted sand for liquefaction mitigation purposes. Geomechanics and Geoengineering 6(3): 155-170.

Porcino D, Marcianò V and Granata R (2012) Static and dynamic properties of a lightly cemented silicate-grouted sand. Canadian Geotechnical Journal 49(10): 1117-1133.

Promputthangkoon P and Hyde AFL (2007) Compressibility and liquefaction potential of rubber composite soils. In Scrap Tire Derived Geomaterials - Opportunities and Challenges (Hazarika $\mathrm{H}$ and Yasuhara K (eds)). Taylor \& Francis, London, UK, pp. 161-170.

Rao GV and Dutta RK (2006) Compressibility and strength behaviour of sand-tyre chip mixtures. Geotechnical \& Geological Engineering 24(3): 711-724.

Rasouli R, Hayashi K and Zen K (2016) Controlled permeation grouting method for mitigation of liquefaction. Journal of Geotechnical and Geoenvironmental Engineering 142(11): article 4016052.

Rebata-Landa V and Santamarina JC (2012) Mechanical effects of biogenic nitrogen gas bubbles in soils. Journal of Geotechnical and Geoenvironmental Engineering 138(2): 128-137.

Rugg DA, Yoon J, Hwang $\mathrm{H}$ and El Mohtar CS (2011) Undrained shearing properties of sand permeated with a bentonite suspension for static liquefaction mitigation. In Geofrontiers 2011: Advances in Geotechnical Engineering (Han J and Alzamora DA (eds)). American Society of Civil Engineers, Reston, VA, USA, Geotechnical Special Publication 211, pp. 677-686.

Spencer LM, Glenn J and Gallagher PM (2007) Dynamic properties of colloidal silica gel and sand mixtures. Proceedings of the 4th International Conference on Earthquake Geotechnical Engineering, Thessaloniki, Greece, paper no. 1324.

Towhata I (2008) Geotechnical Earthquake Engineering. Springer-Verlag, Berlin, Germany.

Towhata I and Kabashima Y (2001) Mitigation of seismically-induced deformation of loose sandy foundation by uniform permeation grouting. Proceedings Earthquake Geotechnical Engineering Satellite Conference, XVth International Conference on Soil Mechanics and Geotechnical Engineering, Istanbul, Turkey, pp. 313-318. 
Geotechnical Research

Volume 7 Issue 4
Effects of high-diluted colloidal silica

grouting on the behaviour of liquefiable

sand

Ciardi, Bardotti, Vannucchi and Madiai van Paassen LA, Daza CM, Staal M et al. (2010a) Potential soil reinforcement by biological denitrification. Ecological Engineering 36(2): 168-175.

van Paassen LA, Ghose R, van der Linden TJM, van der Star WRL and van Loosdrecht MCM (2010b) Quantifying biomediated ground improvement by ureolysis: large-scale biogrout experiment. Journal of Geotechnical and Geoenvironmental Engineering 136(12): 1721-1728.

Vranna AD and Tika T (2015) Undrained monotonic and cyclic behaviour of a silty sand stabilized with colloidal silica. 6th International Conference on Earthquake Geotechnical Engineering, Christchurch, New Zealand.

Vranna AD and Tika T (2019) Laboratory improvement of liquefiable sand by colloidal silica and weak cementation. Proceedings of the Institution of Civil Engineers - Ground Improvement, https://doi.org/ 10.1680/jgrim.19.00019.

Whang JM (1995) Chemical-based barrier materials. In Assessment of Barrier Containment Technologies for Environmental Remediation
Applications (Rumer RR and Mitchell JK (eds)). National Technical Information Service, Springfield, VA, USA, Section 9, pp. 211-247.

Wong C, Pedrotti M, El Mountassir G and Lunn RJ (2018) A study on the mechanical interaction between soil and colloidal silica gel for ground improvement. Engineering Geology 243: 84-100.

Xiao P, Liu H, Stuedlein AW, Evans TM and Xiao Y (2019) Effect of relative density and biocementation on cyclic response of calcareous sand. Canadian Geotechnical Journal 56(12): 1849-1862.

Yegian MK, Eseller-Bayat E, Alshawabkeh A and Al S (2007) Inducedpartial saturation for liquefaction mitigation: experimental investigation. Journal of Geotechnical and Geoenvironmental Engineering 133(4): 372-380.

Yoon J and El Mohtar CS (2013) Dynamic rheological properties of sodium pyrophosphate-modified bentonite suspensions for liquefaction mitigation. Clays and Clay Minerals 61(4): 319-327.

Zornberg JG, Cabral AR and Viratjandr C (2004) Behaviour of tire shred sand mixtures. Canadian Geotechnical Journal 41(2): 227-241. 